\title{
Article \\ Mechanism of Action of Flavonoids of Oxytropis falcata on the Alleviation of Myocardial Ischemia-Reperfusion Injury
}

\author{
Yang Guo ${ }^{1}$, Ben-Yin Zhang ${ }^{2} \mathbb{D}$, Yan-Feng Peng ${ }^{2}$, Leng Chee Chang ${ }^{3}$, Zhan-Qiang Li $^{1}$, Xin-Xin Zhang ${ }^{4}$ \\ and De-Jun Zhang 1,2,*
}

check for

updates

Citation: Guo, Y.; Zhang, B.-Y.;

Peng, Y.-F.; Chang, L.C.; Li, Z.-Q.;

Zhang, X.-X.; Zhang, D.-J.

Mechanism of Action of Flavonoids

of Oxytropis falcata on the Alleviation

of Myocardial Ischemia-Reperfusion

Injury. Molecules 2022, 27, 1706.

https://doi.org/10.3390/

molecules27051706

Academic Editor: Mourad Elhabiri

Received: 29 January 2022

Accepted: 4 March 2022

Published: 5 March 2022

Publisher's Note: MDPI stays neutral with regard to jurisdictional claims in published maps and institutional affiliations.

Copyright: (C) 2022 by the authors. Licensee MDPI, Basel, Switzerland. This article is an open access article distributed under the terms and conditions of the Creative Commons Attribution (CC BY) license (https:// creativecommons.org/licenses/by/ $4.0 /)$.
1 Research Center for High Altitude Medicine, Key Laboratory of High-Altitude Medicine (Ministry of Education), Key Laboratory of Application and Foundation for High Altitude Medicine Research in Qinghai Province (Qinghai-Utah Joint Research Key Lab for High Altitude Medicine), Qinghai University, Xining 810001, China; 1910020117@qhu.edu.cn (Y.G.); 2014980001@qhu.edu.cn (Z.-Q.L.)

2 College of Eco-Environmental Engineering, Qinghai University, Xining 810016, China; benyinzhang@qhu.edu.cn (B.-Y.Z.); y200901j10538@qhu.edu.cn (Y.-F.P.)

3 Department of Pharmaceutical Sciences, Daniel K. Inouye College of Pharmacy, University of Hawai'i, Hilo, HI 96720, USA; lengchee@hawaii.edu

4 School of Pharmacy, Xi'an Jiaotong Univeristy, Xining 710061, China; zhangxinxin360@mail.xjtu.edu.cn

* Correspondence: djzhang@qhu.edu.cn; Tel.: +86-0971-5310586

\begin{abstract}
Oxytropis falcata Bunge is a plant used in traditional Tibetan medicine, with reported antiinflammatory and antioxidants effects and alleviation of myocardial ischemia reperfusion injury (MIRI). However, the underlying mechanism against MIRI and the phytochemical composition of O. falcata are vague. One fraction named OFF1 with anti-MIRI activity was obtained from O. falcata, and the chemical constituents were identified by ultra-high-performance liquid chromatography coupled with tandem mass spectrometry (UHPLC-MS). The potential targets and signaling pathways involved in the action of $O$. falcata against MIRI were predicted by network pharmacology analysis, and its molecular mechanism on MIRI was determined by in vitro assays. The results revealed that flavonoids are the dominant constituents of OFF1. A total of 92 flavonoids reported in O. falcata targeted 213 potential MIRI-associated factors, including tumor necrosis factor (TNF), prostaglandinendoperoxide synthase 2 (PTGS2), and the NF-kB signaling pathway. The in vitro assay on H9c2 cardiomyocytes subjected to hypoxia/reoxygenation injury confirmed that the flavonoids in OFF1 reduced myocardial marker levels, apoptotic rate, and the inflammatory response triggered by oxidative stress. Moreover, OFF1 attenuated MIRI by downregulating the ROS-mediated JNK/p38MAPK/NF$\mathrm{KB}$ pathway. Collectively, these findings provide novel insights into the molecular mechanism of O. falcata in alleviating MIRI, being a potential therapeutic candidate.
\end{abstract}

Keywords: Oxytropis falcata Bunge; flavonoids; network pharmacology; myocardial ischemia reperfusion injury; JNK/p38MAPK/NF-kB

\section{Introduction}

Ischemic heart disease is a highly prevalent threat worldwide, with a mortality rate of $16 \%$ [1]. Although the timely restoration of myocardial blood flow can reduce the size of the ischemic myocardium, revascularization may also aggravate the functional and structural impairment of the myocardium, thereby resulting in myocardial ischemia reperfusion injury (MIRI) [2,3]. Multiple therapeutic strategies have been applied to manage MIRI, including mechanical physiotherapy (e.g., ischemic pretreatment, ischemic post-treatment, and remote ischemic treatment) [4-6], and pharmacotherapy (e.g., adenosine, cyclosporine A and atrial natriuretic peptide) [7-9]. However, the efficacy of these approaches is limited. Traditional Chinese medicine (TCM) has been widely used in China for thousands of years, and it has better therapeutic effects on various complicated disorders with few side effects [10]. Numerous clinical and experimental studies have demonstrated that Chinese 
medical prescriptions and herbal medicine extracts may play a therapeutic role in MIRI by exerting an anti-inflammatory and anti-apoptotic effect, maintaining calcium homeostasis, providing the clearance of oxygen free radicals, and avoiding platelet aggregation [11-14]. In addition, TCM extracts or mixtures possess more effective pharmacological activities than purified compounds due to their multiple components and targets [15]. Thus, the cardioprotective effects of TCM may provide a therapeutic alternative for MIRI.

Oxytropis falcata Bunge, belonging to the Leguminosae family of perennial herbs, is widely distributed in the northwestern and southwestern regions of China, including Qinghai, Gansu, Tibet, Sichuan, and Xinjiang provinces [16]. As recorded in the Tibetan medicine book Jingzhu Materia Medica, the ability of $O$. falcata to promote blood circulation, relief pain, clearing of heat, and detoxification is well known [17-19]. Moreover, O. falcata is also included in many Chinese herbal formulas, such as Qingpeng ointment, Shierwei Yishou San and Cheezheng Pain Relieving Plaster, which have been applied in clinical practice in China for decades [20-22]. Currently, the compounds isolated and identified from $O$. falcata mainly include flavonoids, alkaloids, and saponins [18]. Furthermore, numerous studies revealed that flavonoids in $O$. falcata are the predominant active compounds responsible for the anti-inflammatory, anti-tumor, and antioxidant effects, as well as anti-cardiovascular diseases [17,23-27]. Therefore, the flavonoids of $O$. falcata are potentially correlated with the protective effects on MIRI. Extensive evidence revealed that flavonoids from other medical plants display diverse protective effects on MIRI. For instance, flavonoids from Theobroma cacao inhibit nitro-oxidative stress, inflammatory response, and apoptosis in MIRI by regulating AKT and NF- $\mathrm{KB}$ signaling pathways [28]. The total flavonoids from Clinopodium chinense alleviate myocardial injury through the modulation of the reactive oxygen species (ROS)-mediated Akt/Nrf2/HO-1 pathway in vivo and in vitro [29]. The flavonoids extracted from Rosa rugosa mitigate MIRI in mice, which is related with the inhibition of JNK and p38 MAPK signaling pathways [30]. Additionally, our previous report also demonstrated that $O$. falcata prevents cardiomyocyte injury induced by hypoxia/reoxygenation (H/R) in vitro and MIRI in vivo by reducing the levels of myocardial injury markers, inhibiting oxidative stress, as well as regulating the expression of apoptotic proteins [23,31-33]. However, to date, the detailed active compounds and molecular mechanisms of $O$. falcata involved in the amelioration of MIRI are still vague.

Unfortunately, TCMs are characterized by complex compositions and unclear mechanisms of action, which seriously hampers their globalization and modernization [34]. However, network pharmacology integrates bioinformatics, omics, pharmacology, and phytochemistry to elucidate the active compounds, multiple targets, synergistic interactions, and potential mechanisms of TCM [35-37]. In recent years, network pharmacology has helped researchers to successfully discover the pharmacological effects and mechanisms of action of Chinese herbal prescriptions (e.g., Huo Tan Chu Shi Decoction, Shexiang Xintong Ning, and Baihe Decoction) [38-40], Chinese medicinal herbs (e.g., Salvia miltiorrhiza, Huangqi, and Shanzha) [41-43], and ingredients of TCMs (e.g., curcumin, quercetin, and triterpenoids) [44-46].

In this study, ultra-high-performance liquid chromatography coupled with tandem mass spectrometry (UHPLC-MS) and network pharmacology were used to identify the potential bioactive components, hub node targets, and key putative pathways of $O$. falcata that mediate its therapeutic effect against MIRI. In addition, the cardioprotective effects of active fraction OFF1 from $O$. falcata were investigated in cardiomyocytes subjected to in vitro $H / R$ injury.

\section{Results}

\subsection{Effect of Different Fractions of O. falcata on H9c2 Cell Injury}

H9c2 myoblasts, a cell model used as an alternative for cardiomyocytes, were treated with fractions from the $O$. falcata extract eluted with different ratios of petroleum ether and ethyl acetate from a silica gel column and then subjected to $H / R$ to explore the fraction with anti-MIRI activity (Figure S1). The results showed that the fraction OFF1 eluted 
with petroleum ether and ethyl acetate (4:1) exerted a significant protective effect against $\mathrm{H} / \mathrm{R}$ injury.

\subsubsection{Effects of OFF1 on Cell Viability}

$\mathrm{H} 9 \mathrm{c} 2$ cells were pretreated with different concentrations of OFF1 and subjected to $\mathrm{H} / \mathrm{R}$; the cell viability of the $\mathrm{H} / \mathrm{R}$ group markedly decreased by approximately $45.75 \%$ compared to the control group (Con) ( $p<0.01$; Figure 1A). However, the cell viability of the OFF1 $(2.5,5,10,25$, and $50 \mu \mathrm{g} / \mathrm{mL})$ groups was 1.03-fold, 1.14-fold, 1.43-fold, 1.76-fold, and 1.85-fold higher than that of the H/R group, respectively ( $p<0.01$; Figure $1 \mathrm{~A})$. The OFF1 pretreatment protected against cell death in a dose-dependent manner compared to the H/R group, and the dose of $50 \mu \mathrm{g} / \mathrm{mL}$ OFF1 was the most effective.

A

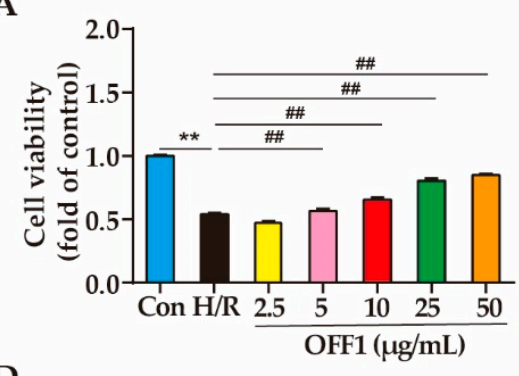

D

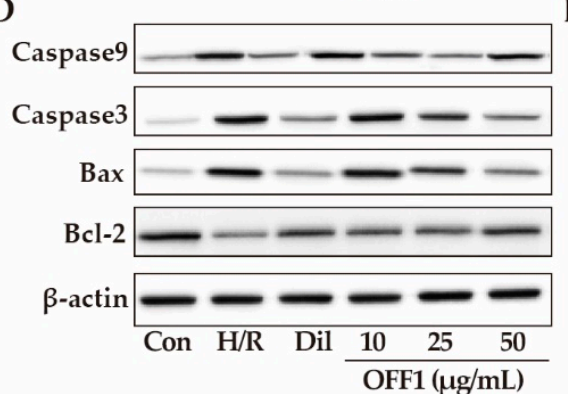

G

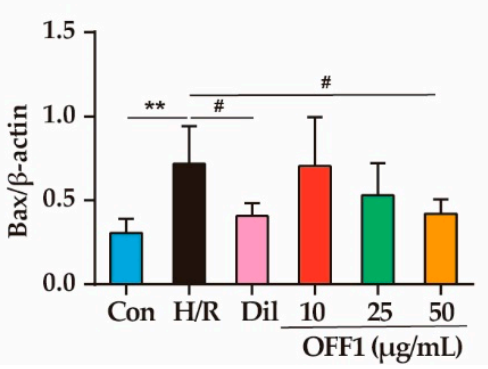

B

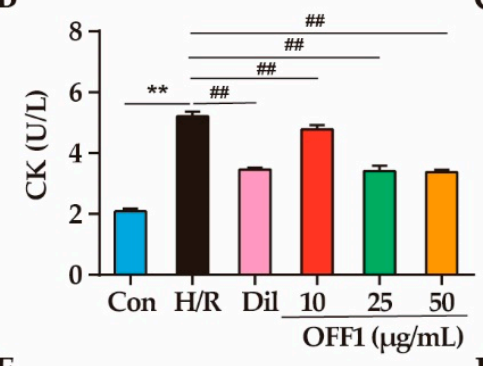

E

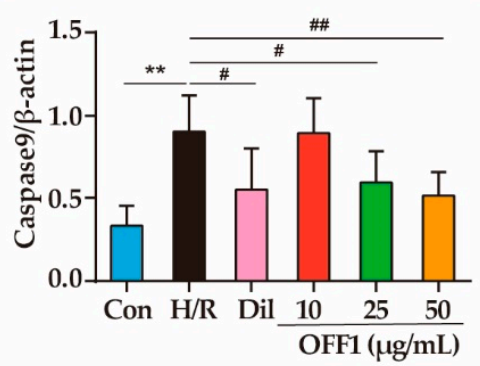

$\mathbf{H}$

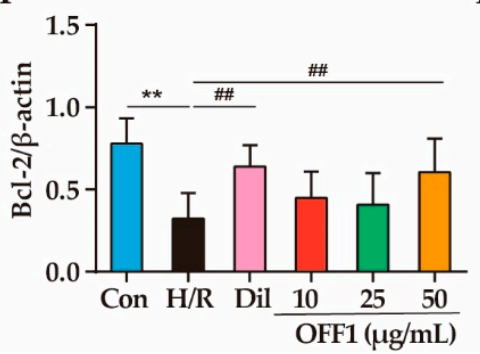

C
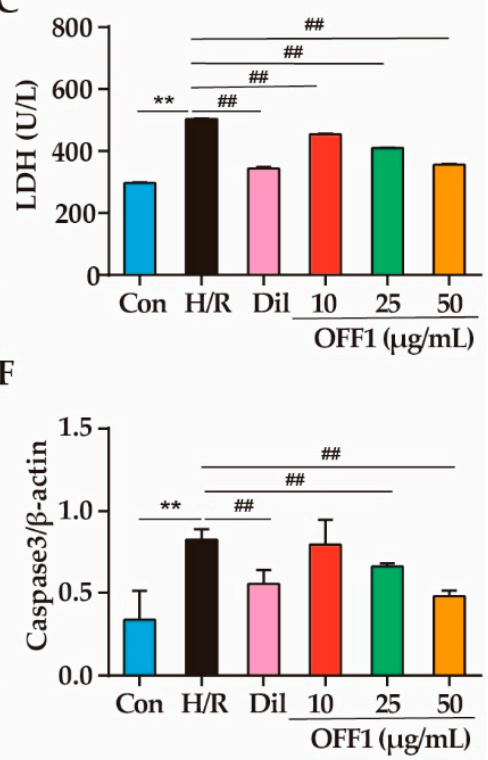

I

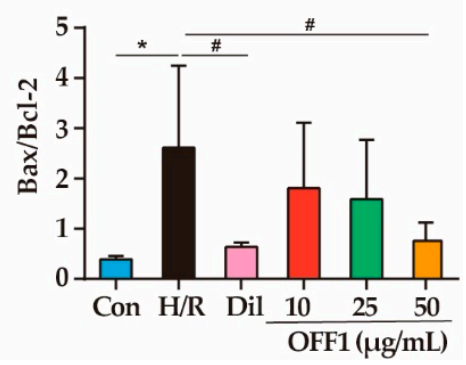

Figure 1. Effects of OFF1 on H9c2 cell injury. (A) Cell viability of H9C2 cells subjected to different treatments $(n=5)$. (B,C) Levels of cardiac markers under different treatments $(n=5)$. (D) Representative immunoblot showing the expression of Caspase9, Caspase3, Bax, and Bcl-2 $(n=3)$. (E-I) Semi-quantitative analyses of Caspase9, Caspase3, Bax, and Bcl-2 proteins $(n=3)$. Results are expressed as mean $\pm \mathrm{SD} .{ }^{*} p<0.05,{ }^{* *} p<0.01$ versus the control group; $\# p<0.05$, \#\# $p<0.01$ versus the H/R group. Con, control group; H/R, hypoxia/reoxygenation; Dil, diltiazem; OFF1, prepared fraction from O. falcata.

\subsubsection{Effects of OFF1 on Cardiomyocyte Damage}

Creatine kinase $(\mathrm{CK})$ and lactate dehydrogenase (LDH) are the markers identifying myocardial damage. CK activity in the cell supernatant of the Con, $H / R$, positive control diltiazem (Dil), and OFF1 (10, 25, and $50 \mu \mathrm{g} / \mathrm{mL})$ groups were $2.08 \pm 0.09,5.21 \pm 0.15$, $3.46 \pm 0.06,4.77 \pm 0.14,3.40 \pm 0.19$, and $3.37 \pm 0.07(\mathrm{U} / \mathrm{L})$, respectively. CK activity decreased approximately $33.59 \%, 8.45 \%, 34.74 \%$, and $27.64 \%$ in the Dil and OFF1 groups, respectively, compared to the $\mathrm{H} / \mathrm{R}$ group $(p<0.01)$ (Figure $1 \mathrm{~B})$. The levels of LDH in the 
cell supernatant of the Con, H/R, Dil, and OFF1 $(10,25$, and $50 \mu \mathrm{g} / \mathrm{mL})$ groups were $296.74 \pm 2.33,503.36 \pm 1.80,343.68 \pm 4.91,454.05 \pm 1.96,409.72 \pm 1.11$, and $355.69 \pm 2.36$, respectively. The LDH levels decreased approximately $31.72 \%, 9.80 \%, 18.60 \%$, and $29.34 \%$ in these groups, respectively, compared to the H/R group $(p<0.01$; Figure $1 \mathrm{C})$.

\subsubsection{Effects of OFF1 on Cell Apoptosis}

$\mathrm{H} / \mathrm{R}$ dramatically increased the expression of pro-apoptotic proteins (Caspase9, Caspase3, Bax) as well as the Bax/Bcl-2 ratio and decreased that of anti-apoptotic protein (Bcl-2) $(p<0.05$ or $p<0.01$; Figure 1D). In contrast, the pretreatment with OFF1 and Dil protected against the effects of $H / R$ injury on the apoptotic proteins $(p<0.05$ or $p<0.01)$, indicating that the OFF1 fraction exerted a protective effect against H/R injury These results encouraged us to further investigate the chemical constituents and mechanism of action of OFF1. Taken together, OFF1 alleviates cell apoptosis in H/R-induced H9c2 cell injury.

\subsection{Identification of the Main Components of OFF1}

The chemical components of OFF1 were analyzed by UHPLC in the ESI negative and positive ion modes (Figure S2). Their accurate molecular formulas and molecular weight were identified by high-accuracy quasi-molecular ions $\left([\mathrm{M}+\mathrm{H}]^{+}\right.$and $\left.[\mathrm{M}-\mathrm{H}]^{-}\right)$with a mass error of $5 \mathrm{ppm}$, and qualitative analyses were mainly completed with MS/MS fragments. The results showed that OFF1 was mainly composed of flavonoids, and 31 of them including daidzein, 7-hydroxyflavone, maackiain, isoliquiritigenin, naringenin, and luteolin were tentatively identified, as shown in Table 1. Among them, Daidzein and maackiain belong to the isoflavone group; 7-hydroxyflavone, naringenin, and luteolin to the flavone group; and isoliquiritigenin to the chalcone group. Therefore, our next focus was primarily on flavonoids from O. falcata.

Table 1. Metabolites tentatively identified in OFF1 by UHPLC-MS in positive and negative ion modes.

\begin{tabular}{|c|c|c|c|c|c|c|}
\hline No. & Name & $\begin{array}{l}\text { Molecular } \\
\text { Formula }\end{array}$ & $\begin{array}{r}\text { Error } \\
(\mathrm{ppm})\end{array}$ & $\begin{array}{c}\text { MW } \\
\text { (Measured) }\end{array}$ & $\begin{array}{c}\mathrm{ESI}+/- \\
(\mathrm{m} / \mathrm{z})\end{array}$ & $\begin{array}{c}\text { MS/MS } \\
\text { Fragment Ions }\end{array}$ \\
\hline 1 & Daidzein & $\mathrm{C}_{15} \mathrm{H}_{10} \mathrm{O}_{4}$ & 1.77 & 254.0584 & $255.1022 / 253.1437$ & $186.9758,204.9867,219.2112,237.2218$ \\
\hline 2 & Pinocembrin & $\mathrm{C}_{15} \mathrm{H}_{12} \mathrm{O}_{4}$ & 1.08 & 256.0738 & $257.0046 /$ & $215.9778,256.2641,210.9722,233.0177$ \\
\hline 3 & 7-Hydroxyflavone & $\mathrm{C}_{15} \mathrm{H}_{10} \mathrm{O}_{3}$ & 2.16 & 238.06351 & $239.1283 / 238.8211$ & $195.1230,239.1073$ \\
\hline 4 & Isoliquiritigenin & $\mathrm{C}_{15} \mathrm{H}_{12} \mathrm{O}_{4}$ & 1.44 & 256.07393 & $257.0046 /-$ & $192.9624,210.9722,215.9778,233.0177$ \\
\hline 5 & $\begin{array}{l}2,4,4^{\prime}- \\
\text { Trihydroxydihydrochalcone }\end{array}$ & $\mathrm{C}_{15} \mathrm{H}_{14} \mathrm{O}_{4}$ & -3.4 & 258.08833 & $-/ 257.1943$ & $219.8445,256.1910$ \\
\hline 6 & Strobopinin & $\mathrm{C}_{16} \mathrm{H}_{14} \mathrm{O}_{4}$ & -2.57 & 270.0885 & $-/ 269.2114$ & $225.1019,228.9878,221.5644,232.3254$ \\
\hline 7 & Sakuranetin & $\mathrm{C}_{16} \mathrm{H}_{14} \mathrm{O}_{5}$ & 2.24 & 286.08476 & $287.0556 /-$ & $121.0292,153.0187,165.0190$ \\
\hline 8 & Formononetin & $\mathrm{C}_{16} \mathrm{H}_{12} \mathrm{O}_{4}$ & 1.02 & 268.0738 & $269.2116 / 267.0655$ & $123.1166,155.1437,251.2016,2215.1795$ \\
\hline 9 & Bryaflavan & $\mathrm{C}_{17} \mathrm{H}_{18} \mathrm{O}_{6}$ & 0.58 & 318.1105 & $319.2024 /-$ & $163.1125,219.1749$ \\
\hline 10 & Luteolin & $\mathrm{C}_{15} \mathrm{H}_{10} \mathrm{O}_{6}$ & -2.7 & 286.0470 & $-/ 285.9279$ & $157.8609,198.8836,213.9066,219.8449$ \\
\hline 11 & Genistein & $\mathrm{C}_{15} \mathrm{H}_{10} \mathrm{O}_{5}$ & 2.36 & 270.0535 & $271.0971 / 269.2114$ & $144.0830,217.1947,225.1028,235.2047$ \\
\hline 12 & Naringenin & $\mathrm{C}_{15} \mathrm{H}_{12} \mathrm{O}_{5}$ & 2.45 & 272.0691 & $273.0887 / 271.2271$ & $200.9438,205.9934,215.1287,245.0923$, \\
\hline 13 & Hispidulin & $\mathrm{C}_{16} \mathrm{H}_{12} \mathrm{O}_{6}$ & -3.07 & 300.0625 & $-/ 299.2583$ & 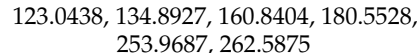 \\
\hline 14 & Glycitein & $\mathrm{C}_{16} \mathrm{H}_{12} \mathrm{O}_{5}$ & 0.52 & 284.0686 & $285.0764 / 283.2633$ & $166.9462,192.9622,214.9700,210.9728$ \\
\hline 15 & $2^{\prime}, 4^{\prime}$-Dihydroxychalcone & $\mathrm{C}_{15} \mathrm{H}_{12} \mathrm{O}_{3}$ & -3.4 & 240.0235 & $-/ 241.1943$ & $219.8445,256.1910$ \\
\hline 16 & Miquelianin & $\mathrm{C}_{21} \mathrm{H}_{18} \mathrm{O}_{13}$ & 3.03 & 478.0762 & $479.0735 / 477.0154$ & $303.0505,229.0504,153.0190$ \\
\hline 17 & $\begin{array}{l}\text { Isorhamnetin } \\
\text { 3-glucuronide }\end{array}$ & $\mathrm{C}_{22} \mathrm{H}_{20} \mathrm{O}_{13}$ & 2.4 & 492.0916 & $493.3905 / 491.2122$ & $153.0189,302.0428,317.0661$ \\
\hline 18 & Lilaline & $\mathrm{C}_{20} \mathrm{H}_{17} \mathrm{NO}_{7}$ & 2.34 & 383.1014 & $384.1614 /-$ & $\begin{array}{c}206.0816,118.0656,160.0769 \\
188.0707,248.0921\end{array}$ \\
\hline 19 & Kaempferol 3-glucuronide & $\mathrm{C}_{21} \mathrm{H}_{18} \mathrm{O}_{12}$ & -2.2 & 462.0788 & $-/ 461.0716$ & $2253.0503,261.9223,320.8129,357.7877$ \\
\hline 20 & Maackiain & $\mathrm{C}_{16} \mathrm{H}_{12} \mathrm{O}_{5}$ & 0.42 & 284.0686 & $285.0764 /-$ & $214.9700,192.9622,210.9729,184.9571$ \\
\hline 21 & 4"'"-Acetylsagittatin A & $\mathrm{C}_{34} \mathrm{H}_{40} \mathrm{O}_{19}$ & 2.57 & 752.2183 & $-/ 751.2076$ & $298.0475,607.1785,426.9629,395.3199$ \\
\hline 22 & Brosimacutin C & $\mathrm{C}_{20} \mathrm{H}_{22} \mathrm{O}_{5}$ & -2.89 & 342.1457 & $-/ 341.1079$ & $216.9878,254.9855,270.5942,337.8138$ \\
\hline 23 & Phloretin & $\mathrm{C}_{15} \mathrm{H}_{14} \mathrm{O}_{5}$ & -2.51 & 274.0834 & $-/ 273.0159$ & $134.4794,146.6030,169.0068,179.8389$ \\
\hline 24 & (S)-Equol & $\mathrm{C}_{15} \mathrm{H}_{14} \mathrm{O}_{3}$ & 1.78 & 242.0947 & $243.1915 /-$ & $111.0926,180.1755,228.1808,107.0865$ \\
\hline 25 & Isovolubilin & $\mathrm{C}_{23} \mathrm{H}_{24} \mathrm{O}_{9}$ & -2.24 & 444.1410 & $-/ 443.1184$ & $193.0493,249.0610,267.0711,149.0591$ \\
\hline 26 & Astragalin & $\mathrm{C}_{21} \mathrm{H}_{20} \mathrm{O}_{11}$ & -2.37 & 448.0995 & $-/ 447.0060$ & $78.9576,148.9995,179.0102,96.9678$ \\
\hline 27 & Rhamnetin & $\mathrm{C}_{16} \mathrm{H}_{12} \mathrm{O}_{7}$ & 1.65 & 316.0588 & $317.6330 /-$ & $167.0349,243.0658,274.0481,302.0421$ \\
\hline 28 & Scrophulein & $\mathrm{C}_{17} \mathrm{H}_{14} \mathrm{O}_{6}$ & 1.71 & 314.07958 & $315.0506 /-$ & $287.0554,231.0657,259.0604,203.0712$ \\
\hline 29 & Isoquercetin & $\mathrm{C}_{21} \mathrm{H}_{20} \mathrm{O}_{12}$ & -2.18 & 464.0945 & $-/ 463.0872$ & $301.1073,405.6862,135.0440,160.8422$ \\
\hline 30 & Isomucronulatol & $\mathrm{C}_{17} \mathrm{H}_{18} \mathrm{O}_{5}$ & -2.03 & 302.0258 & $-/ 301.2122$ & $113.0277,120.0007,181.0848$ \\
\hline 31 & Rutin & $\mathrm{C}_{27} \mathrm{H}_{30} \mathrm{O}_{16}$ & 2.07 & 610.1547 & $611.1619 /-$ & $303.0504,97.0289$ \\
\hline
\end{tabular}




\subsection{Network Pharmacology Analysis}

\subsubsection{Selection of Active Compounds in O. falcata}

A total of 115 flavonoids from $O$. falcata was found through the search of the relevant literature $[18,19,23,27,43,47]$, and among them, 90 active compounds were screened out based on Lipinski's Rule of five [48]. Myricetin and robinin were also taken into consideration due to their previously reported pharmacological effects $[49,50]$ (Table S1). In total, 92 active compounds were used for the evaluation of the target prediction.

\subsubsection{Potential Targets and PPI Network Analysis}

A total of $1167,175,638$, and 178 MIRI-related targets was screened out from GeneCards, Disgnet, GeneCLip 3, and OMIM databases, respectively, and then 1491 targets were considered after removing the duplicates (Table S2). Subsequently, 131, 267, and 331 flavonoidrelated targets were predicted from the databases of SwissTarget Prediction, SEA, and TargetNet, respectively, and 467 targets were considered after the removal of duplicate entries (Table S3). Finally, 213 overlapping targets between MIRI- and flavonoid-related targets were generated, which were likely targeted by flavonoids from O. falcata curing MIRI (Figure 2A, Table S4).

A

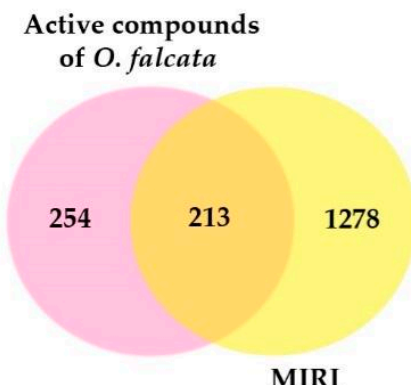

B

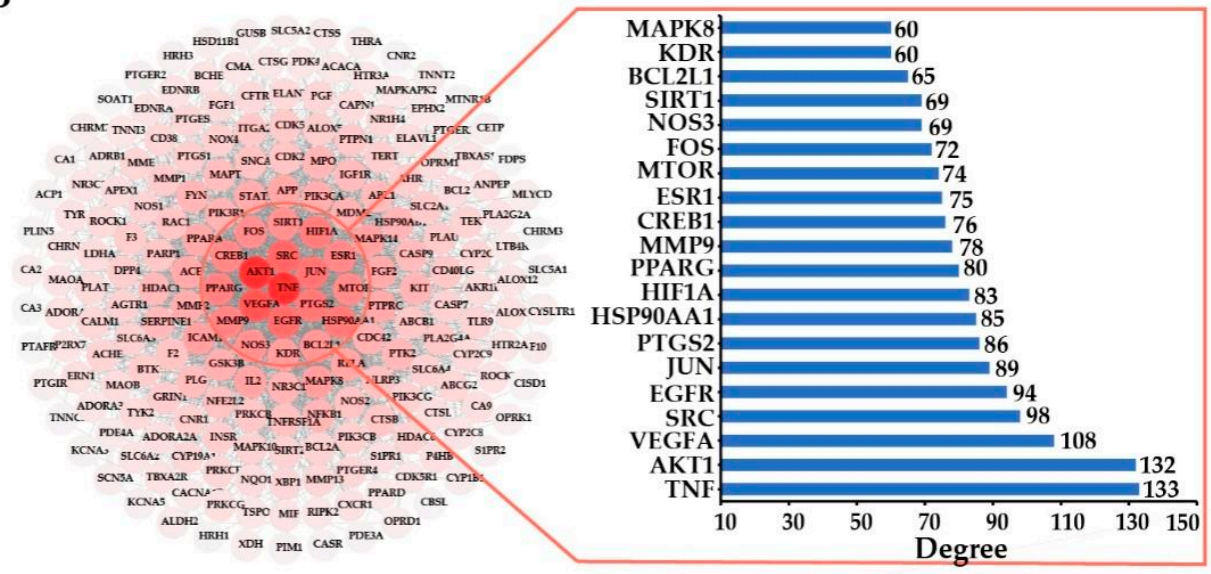

Figure 2. Screening of targets in MIRI. (A) Overlapping flavonoid-related and MIRI-related targets by Venn diagram. (B) Protein-protein interaction network and key crossover targets.

The PPI network was constructed by the STRING online platform in order to clarify the interaction among the intersection targets and screen out the most core targets. The PPI network consisted of 212 nodes and 2897 interactions (Figure 2B). Higher correlation coefficients (degrees) of interacting proteins were indicated by the stronger color intensity of the node. Network topological analysis identified TNF (degree $=133)$, AKT1 (degree $=132)$, VEGFA (degree $=108)$, SRC (degree $=98)$, EGFR (degree $=94)$, JUN (degree $=89)$, and PTGS2 (degree $=86$ ) as the hub targets of flavonoids to protect against MIRI (Table S5).

\subsubsection{Compound-Disease-Target Network Analysis}

The compound-disease-target network was constructed to further evaluate the interaction and correlation between the potential targets of various flavonoids in O. falcata to protect against MIRI. This network consisted of 306 nodes and 4469 edges, and the average number of neighbors was 29.21. A total of 213 targets (green nodes) in MIRI (yellow node) corresponding to 92 active compounds (purple nodes) of O. falcata (blue node) was found, as shown in Figure 3. This result suggested that multiple compounds exerted synergistic effects against MIRI through multiple targets. The network analysis showed that $2^{\prime}, 4^{\prime}$-dihydroxy chalcone (degree $\left.=97\right)$, isoliquiritigenin (degree $\left.=94\right)$, 7-hydroxyflavone $($ degree $=89)$, daidzein $($ degree $=86)$, naringenin $($ degree $=53)$, and luteolin $($ degree $=51)$ might be the key flavonoids in the treatment of MIRI by O. falcata (Table S6). 


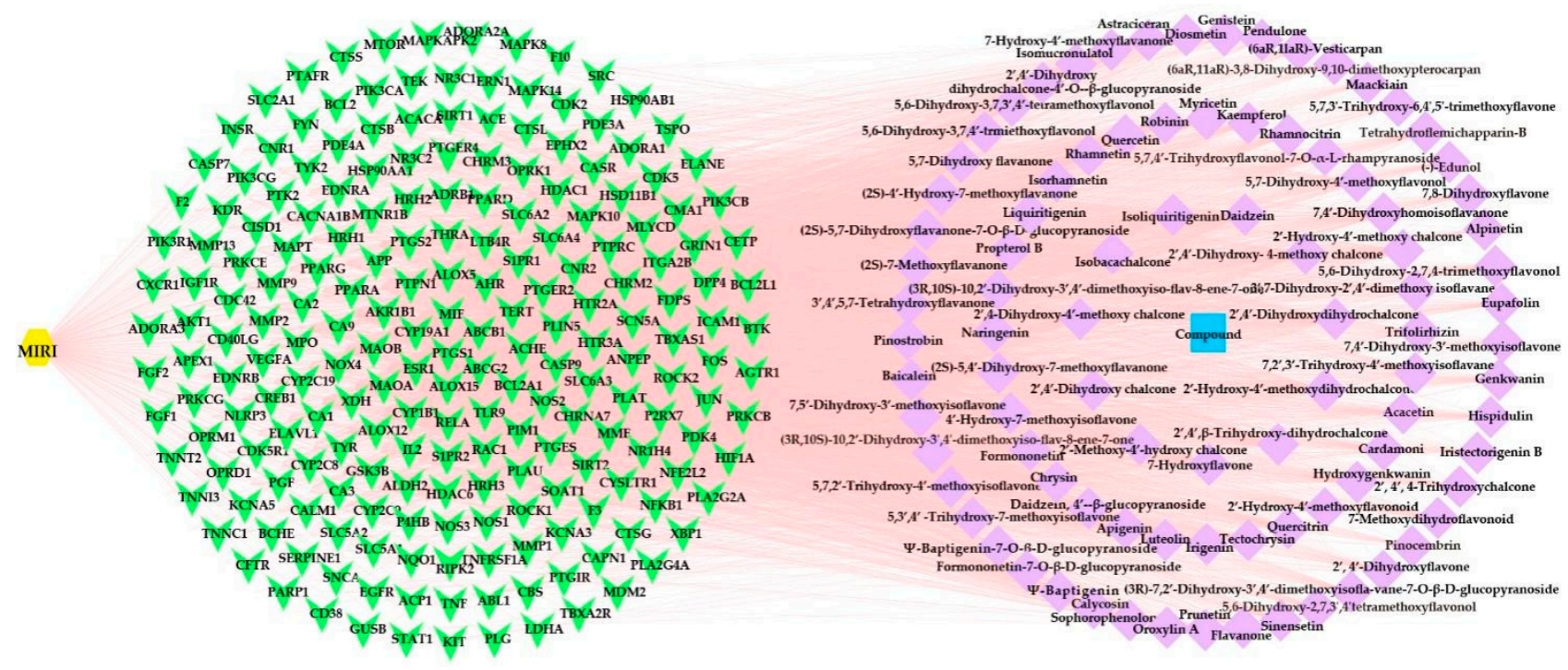

Figure 3. Active compound-MIRI-target network. The yellow hexagons indicate the disease, the green $\mathrm{V}$ indicate 213 targets, the purple squares indicate 92 active compounds, and the blue square indicates drug.

\subsubsection{Functional Enrichment Analyses}

The GO enrichment analysis of the overlapping targets between flavonoids and MIRI was mainly categorized into the biological process (BP; 309 terms), cellular component (CC; 108 terms), and molecular function (MF; 118 terms) (Figure 4A and Tables S7-S9). As regards $\mathrm{BP}$, flavonoids may prevent MIRI by their action on pathways involved in the circulatory system (GO:0003013; $p<0.001)$, cellular response to nitrogen compound (GO:1901699; $p<0.001$ ), positive regulation of protein phosphorylation (GO:0001934; $p<0.001$ ), response to hypoxia (GO:0001666; $p<0.001$ ), regulation of inflammatory response (GO:0050727; $p<0.001$ ), ROS metabolic process (GO:0072593; $p<0.001$ ), and apoptotic signaling pathway (GO:0097190; $p<0.001$ ) (Table S7). In addition, the significant enriched CC terms for the overlapping targets were membrane raft (GO:0045121, $p<0.001)$, perinuclear region of cytoplasm (GO:0048471; $p<0.001$ ), side of membrane (GO:0098552; $p<0.001$ ), distal axon (GO:0150034; $p<0.001$ ), apical part of cell (GO:0045177; $p<0.001$ ), and nuclear envelope (GO:0005635; $p<0.001$ ). The significantly enriched MF terms included kinase binding (GO:0019900; $p<0.001$ ), oxidoreductase activity (GO:0016491; $p<0.001$ ), nitric-oxide synthase regulator activity (GO:0030235; $p<0.001)$, ubiquitin-like protein ligase binding (GO:0044389; $p<0.001$ ), protein phosphatase 2A binding (GO:0051721; $p<0.001$ ), growth factor receptor binding (GO:0070851; $p<0.001$ ), and $\mathrm{G}$ protein-coupled peptide receptor activity (GO:0008528; $p<0.001)$.

KEGG pathway analysis (Figure 4B) further showed that the putative targets played a protective role in cardiovascular diseases by affecting lipid metabolism, signal transduction, and cell growth and death, as well as the immune and circulatory systems. The overlapping targets were assigned to 297 pathways; the top 20 significantly enriched pathways included energy metabolism, inflammation response, and cardiovascular-related pathways, for example the AGE-RAGE signaling pathway in diabetic complications (hsa04933; $p<0.001$ ), cAMP signaling pathway (hsa04024; $p<0.001$ ), platelet activation (hsa04611; $p<0.001$ ), NF- $\mathrm{KB}$ signaling pathway (hsa04064; $p<0.001$ ), adrenergic signaling in cardiomyocytes (hsa04261; $p<0.001$ ), renin-angiotensin system (hsa04614; $p<0.001$ ), and apelin signaling pathway (hsa04371; $p<0.001$ ). Since the NF- $\mathrm{kB}$ pathway plays a pivotal role in preventing MIRI [28], our hypothesis is that flavonoids probably ameliorated MIRI through the regulation of ROS metabolic, anti-apoptotic, antioxidant, and anti-inflammatory effects. 


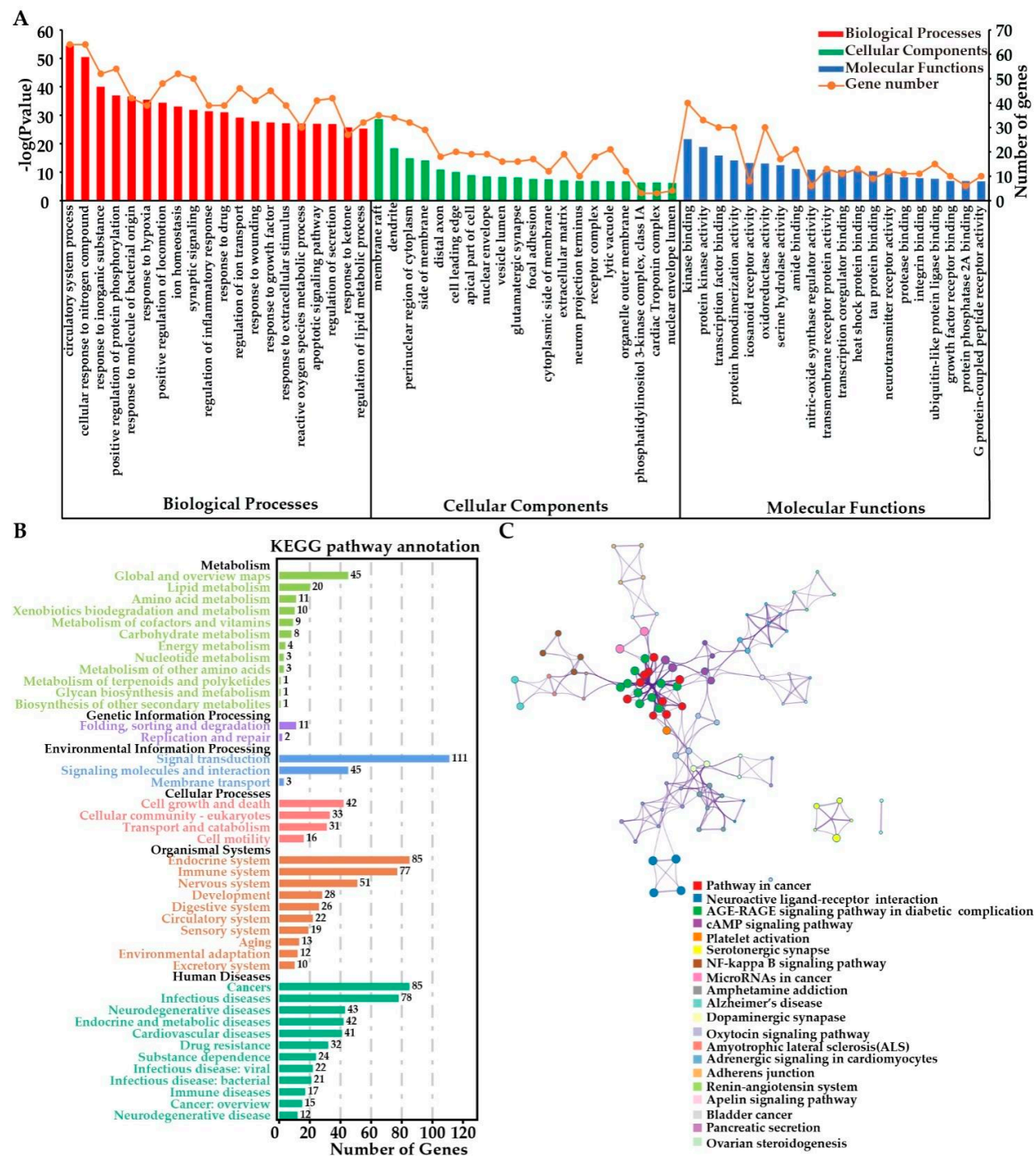

Figure 4. (A) GO enrichment analysis of the overlapping targets. (B) KEGG pathway annotation of the overlapping targets. (C) KEGG pathway analysis of the overlapping targets.

\subsection{Mechanism of Action of OFF1 in the Protection against MIRI In Vitro}

\subsubsection{OFF1 Suppresses the Inflammatory Response}

The mechanism of action of OFF1 in the protection against MIRI was investigated in vitro according to the insights provided by the network pharmacology analysis. H9c2 cells subjected to $H / R$ injury resulted in a significant increase in the cytokine levels of the pro-inflammatory interleukins (IL)- $1 \beta$ and IL-6, monocyte chemoattractant protein (MCP)1 , and tumor necrosis factor (TNF)- $\alpha$ in the supernatant of the cultured cardiomyocytes by 4.30 -fold, 2.59-fold, 2.20-fold, and 1.96-fold, respectively, compared to the Con group $(p<0.01$; Figure 5A-D). Conversely, IL-1 $\beta$ content was significantly reduced by approximately $64.08 \%, 54.57 \%, 69.49 \%$, and $92.59 \%$ in the Dil and OFF1 $(10,25$, and $50 \mu \mathrm{g} / \mathrm{mL}$ ) groups compared with the H/R group, respectively ( $p<0.01$; Figure 5A). IL-6 concentrations in the Dil and OFF1 $(10,25$, and $50 \mu \mathrm{g} / \mathrm{mL})$ groups were lower by approximately $43.90 \%, 18.73 \%, 36.50 \%$, and $52.45 \%$, respectively, than those in the H/R group $(p<0.01$; Figure 5B). MCP-1 levels in the Dil and OFF1 $(10,25$, and $50 \mu \mathrm{g} / \mathrm{mL})$ groups were lower than those in the H/R group by approximately $41.39 \%, 12.12 \%, 24.77 \%$, and $43.38 \%$, respectively ( $p<0.01$; Figure 5C). Moreover, TNF- $\alpha$ level was lower by $35.54 \%, 20.65 \%, 25.47 \%$, and $34.89 \%$ in the Dil and OFF1 $(10,25$, and $50 \mu \mathrm{g} / \mathrm{mL}$ ) groups, respectively, when compared to the H/R group ( $p<0.01$; Figure 5D). These findings indicated that OFF1 alleviated the inflammatory response in $\mathrm{H} 9 \mathrm{c} 2$ cells after $\mathrm{H} / \mathrm{R}$ injury. 


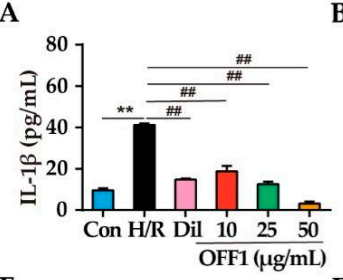

E

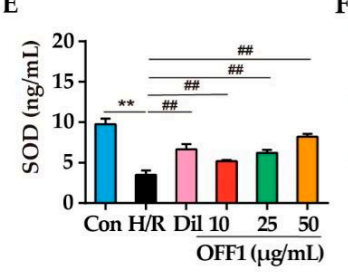

I

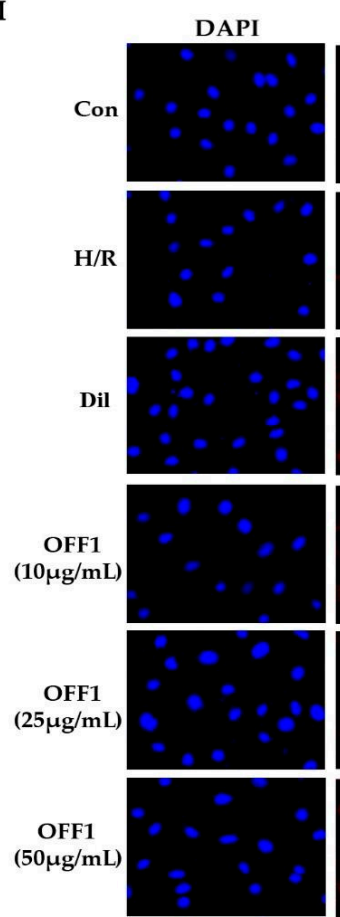

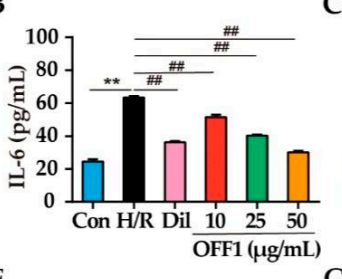

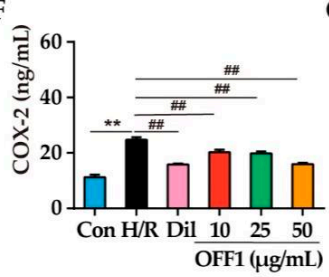

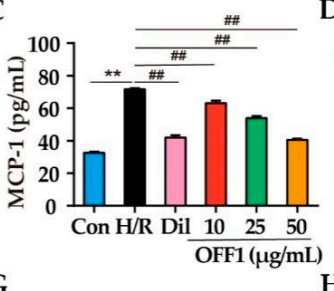

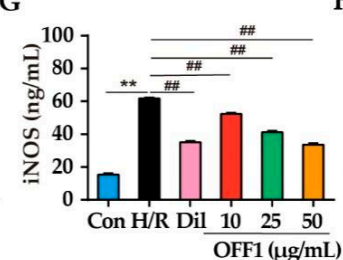

D
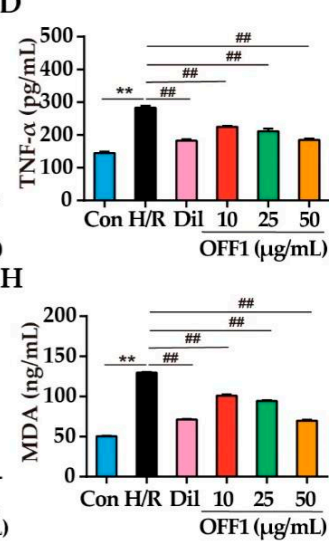

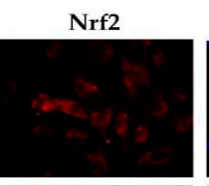

Merge
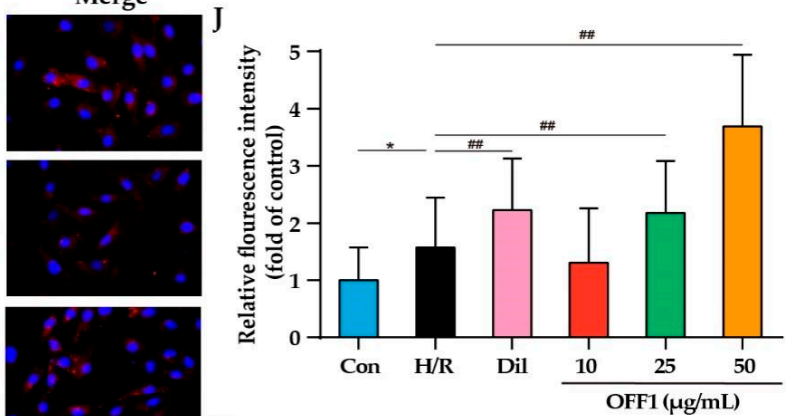

K

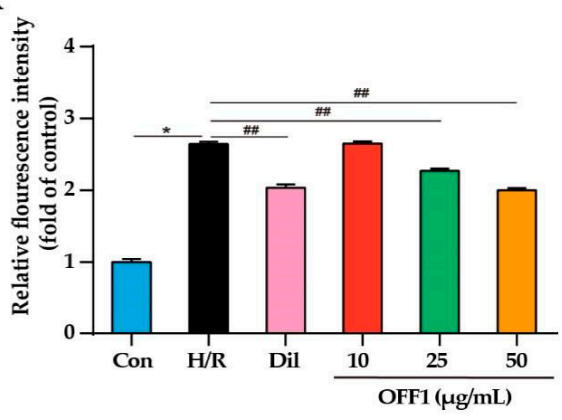

Figure 5. (A-D) Inflammatory cytokines levels in the indicated groups $(n=5)$. (E-H) Oxidative stress markers in the indicated groups $(n=5)$. ( $(\mathbf{I} \mathbf{J})$ Representative images of immunostained cells showing the nuclear localization of Nrf2 $(n=3)$ (400x magnification). The blue fluorescence indicates the nucleus, and the red fluorescence indicates Nrf2. (K) ROS levels in the indicated groups $(n=5)$. Results are expressed as mean $\pm \mathrm{SD} .{ }^{*} p<0.05,{ }^{* *} p<0.01$ versus the control group; \#\# $p<0.01$ versus the H/R group. Con, control group; H/R, hypoxia/reoxygenation; Dil, diltiazem; OFF1, prepared fraction from O. falcata.

\subsubsection{OFF1 Suppresses Oxidative Stress}

$\mathrm{H} 9 \mathrm{c} 2$ cells subjected to $\mathrm{H} / \mathrm{R}$ showed significantly reduced superoxide dismutase (SOD) levels by approximately $64.13 \%$ and increased levels of cyclooxygenase (COX-2), inducible nitric oxide synthase (iNOS), and malondialdehyde (MDA) by 2.20-fold, 4.03-fold, and 2.57-fold, respectively, as shown in Figure 5E-H. The SOD levels in the cell supernatant in the Dil and OFF1 $(10,25$, and $50 \mu \mathrm{g} / \mathrm{mL})$ groups were higher than those of the $\mathrm{H} / \mathrm{R}$ group by approximately 1.91-fold, 1.48-fold, 1.78-fold, and 2.34-fold, respectively ( $p<0.01$; Figure 5E). COX-2 was lower by $36.00 \%, 18.02 \%, 19.54 \%$, and $35.44 \%$ in the Dil and OFF1 $(10,25$, and $50 \mu \mathrm{g} / \mathrm{mL})$ groups, respectively, compared with the H/R group $(p<0.01$; Figure $5 \mathrm{~F})$. iNOS content in the Dil and OFF1 $(10,25$, and $50 \mu \mathrm{g} / \mathrm{mL}$ ) groups was significantly decreased by approximately $42.96 \%, 15.26 \%, 33.21 \%$, and $45.40 \%$, respectively, compared with the $\mathrm{H} / \mathrm{R}$ group $(p<0.01$; Figure 5G). Additionally, the MDA concentration in the Dil and OFF1 (10, 25, 
and $50 \mu \mathrm{g} / \mathrm{mL}$ ) groups were lower by approximately $45.06 \%, 27.29 \%, 22.09 \%$, and $46.15 \%$, respectively, than that in the $\mathrm{H} / \mathrm{R}$ group $(p<0.01$; Figure $5 \mathrm{H})$. It is well established that $\mathrm{ROS}$ can trigger oxidative stress, inflammation response, and apoptosis in the myocardium, thus mediating MIRI or H/R injury [51]. Cells subjected to H/R showed significantly reduced ROS levels, which were attenuated by OFF1 or Dil in a dose-dependent manner $(p<0.01)$, as shown in Figure 5K. Collectively, these results revealed that OFF1 inhibited oxidative stress in the $\mathrm{H} 9 \mathrm{c} 2$ cells after $\mathrm{H} / \mathrm{R}$ injury.

\subsubsection{OFF1 Activates the Nrf2 Signaling Pathway}

Previous studies showed that Nrf2 activation protects cardiomyocytes from oxidative stress-induced damage, and the level of intracellular ROS depends on the expression of the endogenous antioxidant Nrf2 $[52,53]$. Therefore, the ability of OFF1 to increase the expression of Nrf2 in H9c2 cells subjected to H/R injury was evaluated. OFF1 pretreatment significantly increased Nrf2 expression in the nuclei of the cardiomyocytes compared to the untreated H/R group ( $p<0.01$; Figure 5I,J). This result indicated that OFF1 could protect cardiomyocytes from oxidative injury by activating the Nrf2 signaling pathway.

\subsubsection{OFF1 Alleviates H/R Injury in Cardiomyocytes through the NF- $\mathrm{B}$ Pathway}

The NF- $\mathrm{BB}$ pathway was analyzed in the $\mathrm{H} 9 \mathrm{c} 2$ cells subjected to $\mathrm{H} / \mathrm{R}$ injury to further clarify the cardioprotective mechanism of OFF1. The levels of NF-kBp65 in the Con, H/R, Dil, and OFF1 (25 and $50 \mu \mathrm{g} / \mathrm{mL})$ groups were $0.93 \pm 0.07,1.84 \pm 0.06,1.30 \pm 0.04$, $1.86 \pm 0.08,1.47 \pm 0.07$, and $1.25 \pm 0.05(\mathrm{U} / \mathrm{L})$, respectively. The NF- $\mathrm{kBp} 65$ levels were decreased by approximately 29.18\%, 19.71\%, and 31.79\% in the Dil and OFF1 (25 and $50 \mu \mathrm{g} / \mathrm{mL}$ ) groups, respectively, when compared with the H/R group $(p<0.01$; Figure 6A).

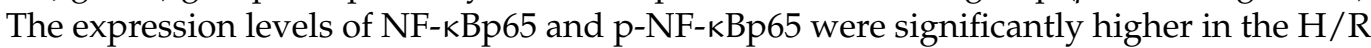
group compared to the control group $(p<0.01)$ and decreased in cells pretreated with Dil and OFF1, as seen in Figure 6B-D. H/R stimulation promoted the nuclear translocation of NF-kBp65, which was suppressed by Dil and OFF1 $(p<0.01$ or $p<0.01)$, as shown in Figure 6E,F. Hence, OFF1 could alleviate H9c2 cell injury induced by H/R by inhibiting the NF-кB signaling pathway.

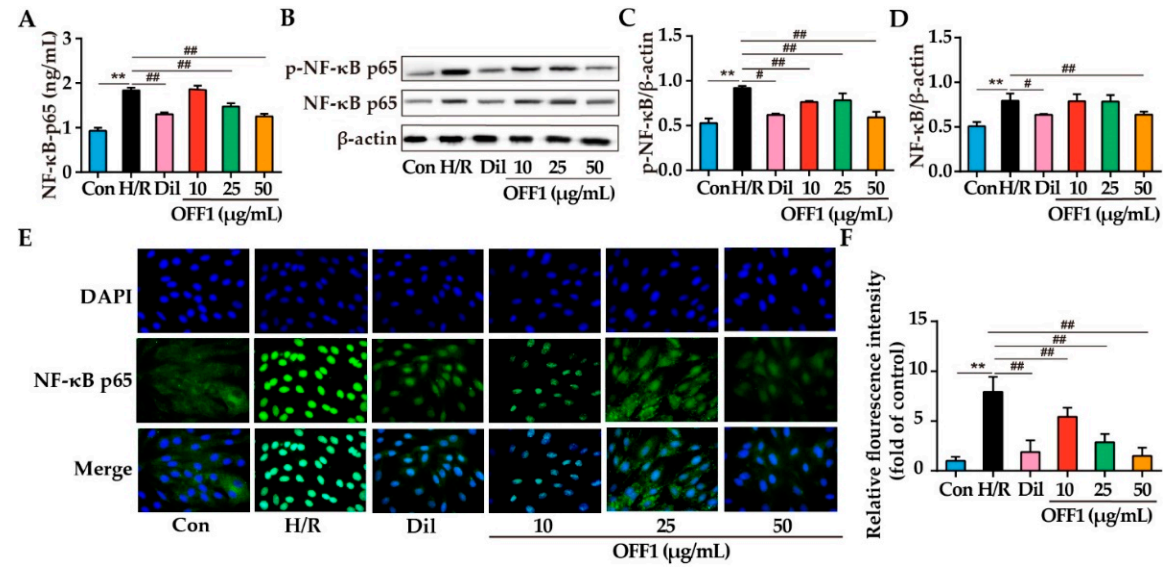

Figure 6. OFF1 alleviated H9c2 injury by the inhibition of the NF- $\mathrm{BB}$ pathway. (A) NF- $\mathrm{kBp} 65$ levels in the indicated groups $(n=5)$. (B) Representative immunoblots showing the expression of NF- $\mathrm{kBp} 65$

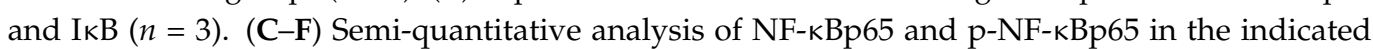
groups. (E) Representative images of immunostained cells showing the nuclear localization of NFкBp65 ( $n=3)(400 \times$ magnification). (F) Relative fluorescence intensity of nuclear Nrf2. The blue fluorescence represents the nucleus, and the green fluorescence represents NF- $\kappa$ Bp 65 . Results are expressed as mean $\pm \mathrm{SD}$. ${ }^{* *} p<0.01$ versus the control group; $\# p<0.05$, \#\# $p<0.01$ versus the $\mathrm{H} / \mathrm{R}$ group. Con, control group; H/R, hypoxia/reoxygenation; Dil, diltiazem; OFF1, prepared fraction from O. falcata. 
2.4.5. OFF1 Alleviates H/R Injury in Cardiomyocytes through the JNK/p38MAPK Pathway

Previous studies showed that JNK and p38MAPK are involved in the inhibition of NF- $\mathrm{kB}$ induced by different compounds [54,55]. The expression and phosphorylation of JNK and p38MAPK induced by OFF1 was examined to clarify whether JNK and p38MAPK are involved in the inhibition of NF- $\mathrm{KB}$. H/R injury was associated with a significant increase in the expression of p-JNK, JNK, p-p38, and p38 $(p<0.01)$, and it was reduced by OFF1 $(p<0.05$ or $p<0.01)$, as shown in Figure 7A-G. Dil exerted a similar effect on the MAPK pathway after $\mathrm{H} / \mathrm{R}$ injury $(p<0.05$ or $p<0.01)$. Taken together, OFF1 mitigated the effects of H/R injury on cardiomyocytes by inhibiting the JNK/p38 MAPK signaling.

A

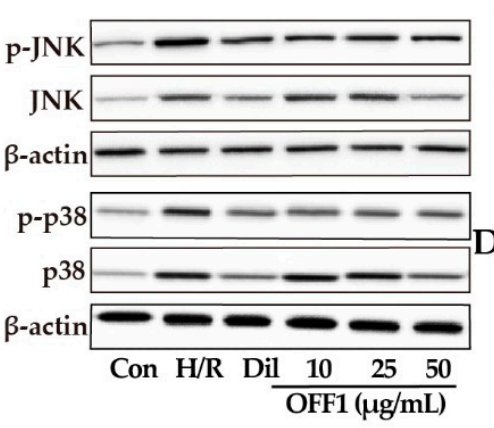

B

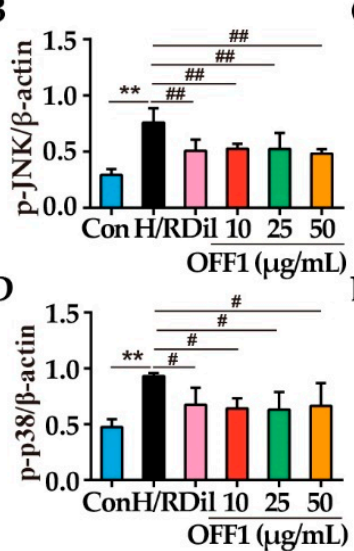

C

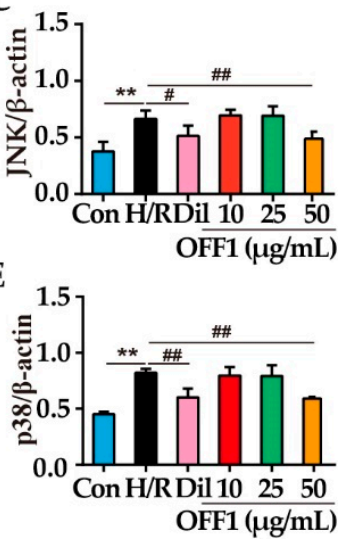

Figure 7. OFF1 attenuated H9c2 injury through the regulation of the MAPK pathway. (A) Representative immunoblot showing the expression of JNK and p38 $(n=3)$. (B-E) Semi-quantitative analysis of $\mathrm{p}-\mathrm{JNK}, \mathrm{JNK}, \mathrm{p}-\mathrm{p} 38$, and $\mathrm{p} 38$ in the indicated groups. Results are expressed as mean $\pm \mathrm{SD}$. ${ }^{* *} p<0.01$ versus the control group; \# $p<0.05$, \#\# $p<0.01$ versus the H/R group. Con, control group; $H / R$, hypoxia/reoxygenation; Dil, diltiazem; OFF1, prepared fraction from $O$. falcata.

\section{Discussion}

MIRI is a complex physiological and pathological process, mainly due to arterial bypass, thrombolytic therapy, and percutaneous coronary angioplasty in the recovery of cardiac tissue and organ blood flow [56]. In recent years, several studies have focused on the pharmacological and mechanical treatment of MIRI, although currently no approved therapy is available to improve the clinical outcomes and reduce the risk of MIRI $[57,58]$. TCMs have the advantages of high efficiency and low toxicity, thanks to their multiple targets [59]. O. falcata is used in Tibetan Medicine to treat several diseases, including leprosy, rheumatic pain, back pain, influenza, and tonsillitis [47]. Several anti-MIRI drugs have been developed from plant-derived natural compounds in recent years, exhibiting multiple pharmacological activities [60-62]. In addition, our previous studies found that the extracts of $O$. falcata have a protective effect on MIRI, although the specific mechanism was not clear $[23,31,33]$. Since the $\mathrm{H} 9 \mathrm{c} 2$ cell line has similar membrane morphology and electrophysiological features as primary cardiomyocytes [63], it could be used as the optimal cell line for inducing $\mathrm{H} / \mathrm{R}$ injury in vitro.

The present study evaluated a bioactive fraction of $O$. falcata called OFF1, which could protect $\mathrm{H} 9 \mathrm{c} 2$ cell subjected to $\mathrm{H} / \mathrm{R}$ from cell death, inhibit the release of CK and LDH, reduce apoptotic proteins such as Caspase9, Caspase3, and Bcl-2, as well as increase the levels of Bax and the ratio of Bax/Bcl-2. These findings demonstrated that OFF1 could protect $\mathrm{H} 9 \mathrm{c} 2$ cell injury by suppressing cell apoptosis. The predominant component were flavonoids, including daidzein, 7-hydroxyflavone, maackiain, isoliquiritigenin, naringenin, and luteolin, which were identified by UHPLC-MS/MS analysis. Therefore, flavonoids probably exerted a crucial role in alleviating MIRI by O. falcata, accordingly providing a basis for the prediction of targets by network pharmacology analysis. Thus, the role of flavonoids of $O$. falcata were investigated. The analysis of network pharmacology revealed 
the intricate interactions among drug components, disease targets, signaling pathways, and molecular mechanisms of TCMs [11,63].

A total of 92 flavonoids of $O$. falcata was evaluated using Lipinsky's RO5, and myricetin and robinin were additionally included due to their established pharmacological effects. For example, myricetin alleviates MIRI by up-regulating COX-2 and cytochrome P450 and p38, and downregulating fatty acid synthase antibody and glucose 6-phosphatedehydrogenase signaling pathway, thus reducing myocardial infarction, apoptosis, inflammation response, and oxidative stress [64]. Robinin reduces the levels of cardiac markers, antioxidant enzymes, lipid peroxidation products and inflammatory markers in cardiac tissue by regulating the TGF- $\beta 1$ signaling pathway [65]. The major bioactive compounds (e.g., $2^{\prime}, 4^{\prime}$-dihydroxy chalcone, chrysin, isoliquiritigenin, 7-hydroxyflavone, daidzein, luteolin, and naringenin) of $O$. falcata were identified by the compound-target-disease network (Table S3). Although the active compounds did not clarify the predicted results (e.g., daidzein, 7-hydroxyflavone, maackiain, isoliquiritigenin, naringenin, and luteolin) of UHPLC-MS, the main flavonoids were consistent with the analysis. In this regard, our results were consistent with previous reports. For example, daidzein improves the left ventricular diastolic pressure and reduces inflammatory cytokines and apoptosis in a rat model of MIRI by regulating the NF- $\kappa B$ signaling pathway [66]. Luteolin markedly alleviates myocardial injury and cardiac dysfunction by activating the PI3K/Akt pathway and inhibiting the Siti1/NLRP3/NF-кB and ROS-mediated MAPK pathways $[67,68]$. In addition, naringenin protects against MIRI by regulating the NRF2/System xc-/GPX4 axis and cGMP-PKGI $\alpha$ signaling pathway $[69,70]$. Other compounds of $O$. falcata such as 7-hydroxyflavone and isoliquiritigenin also exert anti-inflammatory and antioxidant effects and can attenuate diabetic cardiomyopathy [71-73]. The putative targets in MIRI were also identified by PPI network analysis and included TNF, AKT1, VEGFA, SRC, EGFR, JUN, and PTGS2 as the core genes. Studies confirmed that TNF activates JNK and NF- $\mathrm{B}$ by recruiting downstream signaling proteins, therefore aggravating MIRI [54,74]. The immunosuppressant azathioprine protects against MIRI by ameliorating oxidative stress, cell apoptosis, and inflammation by inhibiting the AKT1/GSK3 $\beta$ pathway [75]. VEGFA also plays a vital role in angiogenesis, vascular permeability, and inflammation [76]. Angiogenesis promotes collateral circulation around the ischemic tissue and restores myocardial blood flow, thereby greatly improving the efficacy and prognosis of patients with MIRI [77]. PTGS2, also known as COX-2, is activated in the early stage of inflammation, which is the key pathological mechanism of MIRI [78]. Consistent with the predicted results, OFF1 decreased TNF- $\alpha$ and COX-2 production in H9c2 cells subjected to H/R in vitro.

GO and KEGG analyses further indicated that the flavonoids of $O$. falcata could exert protective effects on cells subjected to MIRI by regulating the circulatory system, ROS metabolic process, inflammatory response, and cell apoptosis, which are correlated with the NF- $\mathrm{B}$ signaling pathway. ROS broadly refers to oxygen-derived free radicals and non-free radicals; the over-production of ROS provokes the inflammatory response, exacerbates endotheliocytes dysfunction, and accelerates cell apoptosis, contributing to cardiac remodeling [79]. MIRI is associated with the overaccumulation of ROS, which promotes the apoptosis of cardiomyocytes by the inhibition of the MAPK signaling pathway [80], which lies upstream of the NF-kB and Nrf2 pathways [54,55]. Other studies also demonstrated that fullerol alleviates the inflammatory response by inhibiting ROS/p38MAPK/NF- $\mathrm{B}$ and ROS/p38MAPK/FoxO1 pathways [81]. In the MIRI model of NADPH oxidase knockout mice, ROS production is reduced, and the myocardial infarction area is also reduced [82]. In the H9c2 cells injured by H/R, activation of the SIRT1/FOXO1/Mn-SOD antioxidant signaling pathway reduces $\mathrm{H} / \mathrm{R}$-induced $\mathrm{ROS}$ production, playing a protective role in cardiomyocytes [83]. Previous studies also showed that the activation of inflammatory factors in the MIRI process induces inflammatory reactions, resulting in local tissue degeneration and necrosis, accompanied by the destruction of the cell membrane, which further aggravates the necrosis and apoptosis of cardiomyocytes, leading to mitochondrial dysfunction [84]. Moreover, the inflammatory response caused by MIRI results in the con- 
tinuous release of pro-inflammatory cytokines such as IL-6, TNF- $\alpha$, ROS, and neutrophils. Neutrophils and ROS cause myocardial tissue damage through the lipid peroxidation of the cell membrane, protein denaturation, and DNA damage [85]. Notably, MIRI induces numerous death receptors such as apoptosis-related factors, tumor necrosis factors, and apoptosis-inducing ligands related to tumor necrosis factors. These receptors interact with the corresponding ligands to form death signal complexes, thereby inducing apoptosis [86].

Therefore, the ROS metabolic process, inflammatory response, cell apoptosis, and NF- $\mathrm{BB}$ signaling pathway closely related to the pathogenesis of MIRI were evaluated in cell experiments to discover their upstream and downstream mechanisms. MAPK acts as an upstream regulator of NF- $\mathrm{B}$, which includes JNK and $\mathrm{p} 38 \mathrm{MAPK}$ signaling pathways. The levels of inflammatory cytokines (e.g., IL-1 $\beta$, IL-6, MCP-1, and TNF- $\alpha$ ), oxidative stress-related cytokines (e.g., ROS, SOD, COX-2, iNOS, MDA, MCP-1, and Nrf2), and the relative expression and phosphorylation of NF- $\mathrm{KBp} 65, \mathrm{JNK}$, and p38 were analyzed in the cardiomyocytes subjected to $\mathrm{H} / \mathrm{R}$ injury. Our findings revealed that OFF1 protects cardiomyocytes from $\mathrm{H} / \mathrm{R}$-induced injury by inhibiting cell apoptosis, inflammation response, and oxidative stress by regulating the ROS-mediated JNK/p38MAPK/NF- $\mathrm{BB}$ pathway (Figure 8). These experimental findings were consistent with the predicted results and previous studies. For example, a study demonstrated that p38MAPK and JNK promote I/R, potentially playing an important role on MIRI [87]. The study of Liu et al. showed that mangiferin alleviates MIRI by inhibiting the MAPK/Nrf-2/HO-1/NF- $\mathrm{B}$ pathway [54]. The protective mechanism of febuxostat in MIRI also depends on the inactivation of the MAPK/NF-кBp65/TNF- $\alpha$ signaling pathway [74]. NEAT1 aggravates MIRI by increasing the levels of myocardial enzymes, ROS, cardiomyocyte apoptosis, and inflammatory factors through the activation of the MAPK signaling pathway [88]. These findings showed that JNK, p38MAPK, and NF-KB could be potential targets in the treatment of MIRI by O. falcata, although multiple other signaling pathways and targets screened by the network pharmacology analysis need to be confirmed by functional studies.

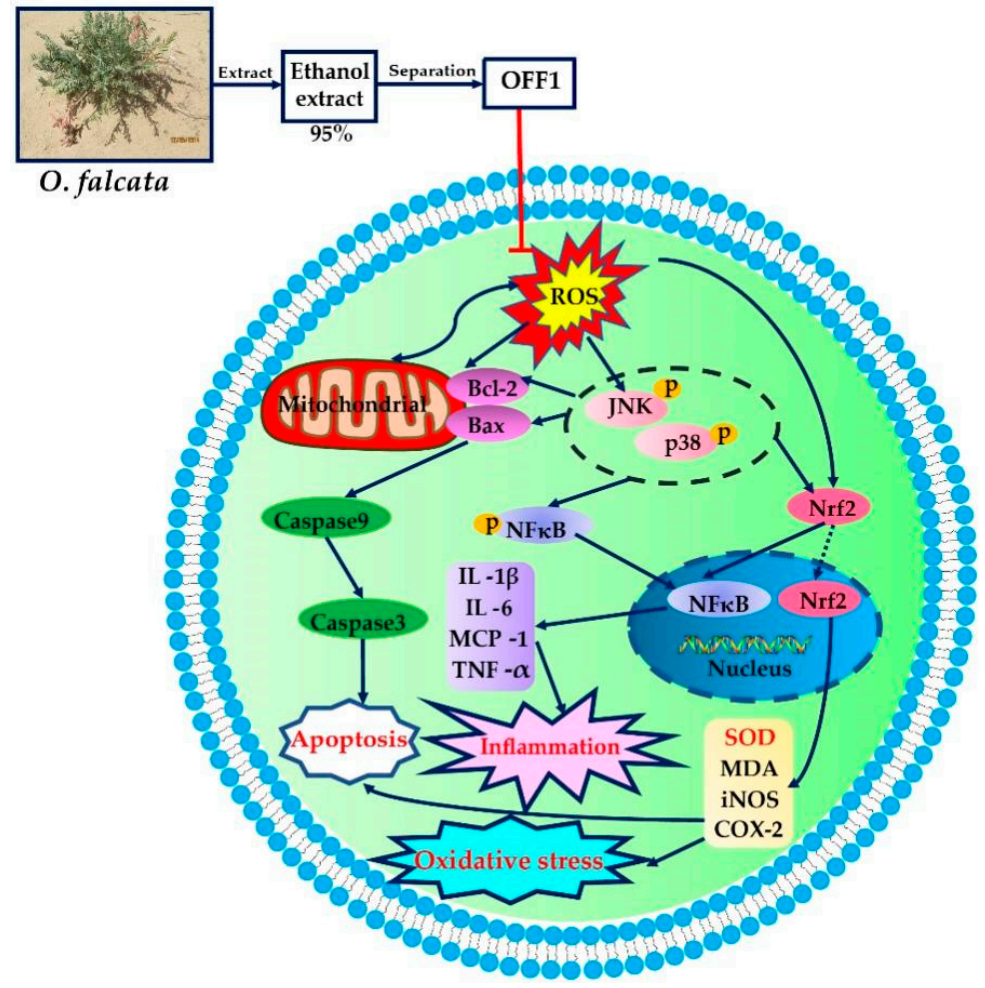

Figure 8. OFF1 protects cardiomyocytes from $\mathrm{H} / \mathrm{R}$ injury by regulating the ROS-mediated JNK/p38MAPK/NF-kB pathway. 


\section{Materials and Methods}

\subsection{Preparation of the Active Fraction of O. falcata}

O. falcata was collected in 2015 from Gonghe County, Qinghai Province, China, and identified by professor Yongchang Yang, Northwest Plateau Institute of Biology. A voucher specimen of $O$. falcata was stored at College of Eco-Environmental Engineering, Qinghai University, as ZHANG2015-O18. One kilogram of the plant matter was ground into powder and extracted with $95 \%$ ethanol (10 L each time) at $75{ }^{\circ} \mathrm{C}$ under reflux for $3 \mathrm{~h}$ three times. The extracts were filtered, combined, and evaporated under reduced pressure to obtain a concentrated O. falcata extract [23]. The ethanol extract was resuspended in water and then extracted sequentially with petroleum ether and chloroform. The chloroform extract was subjected to a silica gel (Nano Micro Technology Co., Ltd., Suzhou, China) column (100-200 mesh) and eluted using a gradient system with petroleum ether and ethyl acetate (10:1 to 1:1). Then, 10 fractions were collected and concentrated by vacuum evaporator. These fractions were used for further pharmacological assays.

\subsection{Identification of Main Compounds in Bioactive Fraction}

We obtained an OFF1 of $4.6 \mathrm{~g}$. The fraction OFF1 was selected and identified by ultra-high-performance liquid chromatography (thermoultimate 3000) coupled to mass spectrometry (UHPLC-MS, Thermo Scientific, Pleasanton, CA, USA) according to our previous report [23]. The chromatographic conditions were as follows: Hypersil GOLD aQ C18 (2.1 mm $\times 100 \mathrm{~mm}, 1.9 \mu \mathrm{m})$; column temperature: $40{ }^{\circ} \mathrm{C}$; flow rate: $0.4 \mathrm{~mL} / \mathrm{min}$; mobile phase: acetonitrile $(\mathrm{A})$ and water $(\mathrm{B})$; gradient elution program: $2 \% \mathrm{~A}(0-2 \mathrm{~min})$, 2-98\% A (2-15 min). The mass spectrometric conditions were as follows: ion source: HESI-source (positive and negative ion mode); capillary temperature: $320^{\circ} \mathrm{C}$; auxiliary gas temperature: $350{ }^{\circ} \mathrm{C}$; sheath gas: $40 \mathrm{arb}$; aux gas: $10 \mathrm{arb}$; spray voltage: $4.00 \mathrm{kV}(+) / 2.80$ $\mathrm{kV}$ (-); resolution: 70,000 (full scan), 17,500 (dd-MS2); normalized collision energy: 20, 30, $40 \mathrm{Ev}$; scan range: 100-1500 m/z. We identified the main compounds in bioactive fraction by Predicted Compositions, mzCloud Search, MassList Search, mzVault Search and ChemSpider Search Library.

\subsection{Identification of Active Flavonoid Compounds in O. falcata}

The flavonoids in O. falcata were obtained from the relevant literature. The 2D structure of the flavonoids was drawn using Chemdraw 18.0, and the Smile structure was derived. Lipinski's Rule of five (RO5), including molecular weight $(\mathrm{MW})<500$, the number of hydrogen bond donors $(\mathrm{nOHNH})<5$, number of hydrogen bond acceptors $(\mathrm{nOH})<10$, lipid-water partition coefficient $(\operatorname{miLog} P)<5$, and number of rotatable keys $($ nRotb) $\leq 10$ was applied to screen for flavonoids relevant to drug development (https:/ / fafdrugs4.com, accessed on 15 April 2021). In addition, a few active compounds that did not meet the RO5 were included due to their high bioactivity.

\subsection{Prediction of Active Compound-Related and MIRI-Related Targets}

The compound-related targets in Homo sapiens were downloaded from the SwissTarget Prediction (http:/ / www.swisstargetprediction.ch/, accessed on 15 April 2021), SEA (http:/ / sea.bkslab.org, accessed on 15 April 2021), and TargetNet (http:/ / targetnet. scbdd.com, accessed on 15 April 2021) databases. The criterion for the selection was the probability value (SwissTarget Prediction, accessed on 15 April 2021), Max Tc (SEA) or prob score (TargetNet) $\geq 0.4$. MIRI-related targets were collected from GeneCards (https:/ /www. genecards.org/, accessed on 15 April 2021), Disgnet (https:/ / www.disgenet.org/search, accessed on 15 April 2021), GeneCLip 3 (http: / / ci.smu.edu.cn/genclip3/analysis.php, accessed on 15 April 2021), and OMIM (https:/ / www.omim.org/, accessed on 15 April 2021) databases. UniprotKB (https:/ / www.uniprot.org/) was used to standardize all targets to UniProt ID and gene name. The active compounds overlapping with MIRI-related targets were identified through Venn diagrams using Omicshare (https: / www.omicshare.com/, accessed on 15 April 2021) to further evaluate the cardioprotective bioactive compounds. 


\subsection{Construction and Analysis of the PPI Network}

The shared protein targets were incorporated into the STRING database (https:/ / string-db.org/, accessed on 16 April 2021), and those with connection score 0.4 were used to construct the PPI network. Cytoscape 3.7.2 was used to visualize the PPI network. The hub targets were calculated by the Degree method of the Cytohubba plugin. Higher node degree was indicative of a stronger association among the target genes.

\subsection{Construction of Drug-Compound-Gene-Disease Network}

Cytoscape 3.7.2. was used to construct the "compound-gene-disease" network to determine the relationship between the drug (O. falcata), MIRI, active compounds, and potential targets. The network was analyzed to predict the hub active compounds of O. falcata against MIRI.

\subsection{GO and KEGG Pathway Enrichment Analysis}

GO and KEGG pathway analyses were performed using the metascape network tool (https: / / www.Metascape.com/, accessed on 17 April 2021) to clarify the biological function and pathways associated with the potential targets. The GO terms and KEGG pathways with a $p$-value $<0.05$ were considered significantly enriched.

\subsection{Cell Culture and $H / R$ Modeling}

H9c2 cells (Procell Life Science \& Technology Co., Ltd., Shanghai, China) were cultured in Dulbecco's modified Eagle's medium (DMEM, $4.5 \mathrm{~g} / \mathrm{L}$ glucose; GIBCO, San Diego, CA, USA) supplemented with $10 \%(v / v)$ fetal bovine serum (FBS; GIBCO, CA, USA) and $0.1 \%$ penicillin/streptomycin (Solarbio Science \& Technology Co., Ltd., Beijing, China) and cultured at $37^{\circ} \mathrm{C}$ under $5 \% \mathrm{CO}_{2}$. The cells were used for different experiments once they reached $80 \%$ confluency. The cells were cultured in serum-free medium under hypoxic conditions consisting of $2 \% \mathrm{O}_{2}, 5 \% \mathrm{CO}_{2}$, and $94 \% \mathrm{~N}_{2}$ for $12 \mathrm{~h}$, and thereafter under normoxic conditions $\left(95 \%\right.$ air and $5 \% \mathrm{CO}_{2}$ ) for $6 \mathrm{~h}$ for reoxygenation to simulate MIRI in vitro.

\subsection{Cell Viability Assay}

Cells were divided into control, $\mathrm{H} / \mathrm{R}$, and OFF1 groups. The cells were subjected to $\mathrm{H} / \mathrm{R}$ pretreatment with different concentrations of OFF1 $(2.5,5,10,25$ and $50 \mu \mathrm{g} / \mathrm{mL})$ for $12 \mathrm{~h}$, except for the control. A CCK8 assay kit (Elabscience Biotechnology Co., Ltd., Wuhan, China) was used to evaluate cell viability. Briefly, $10 \mu \mathrm{L} \mathrm{CCK}-8$ and $100 \mu \mathrm{L}$ DMEM were added to each well after $\mathrm{H} / \mathrm{R}$ induction, and the cells were incubated for $1 \mathrm{~h}$ at $37^{\circ} \mathrm{C}$. The absorbance of each well was measured at $450 \mathrm{~nm}$ using a microplate reader (5200 Multi; Tanon Science and Technology Co. Ltd. Shanghai, China). After that, cells were divided into six groups: (a) control, (b) H/R, (c) H/R + Dil (20 $\mu \mathrm{mol} / \mathrm{L})$, (d) H/R + $10 \mu \mathrm{g} / \mathrm{mL}$ OFF1, (e) $\mathrm{H} / \mathrm{R}+25 \mu \mathrm{g} / \mathrm{mL}$ OFF1, and (f) $\mathrm{H} / \mathrm{R}+50 \mu \mathrm{g} / \mathrm{mL}$ OFF1.

\subsection{Biochemical Assay}

CK and LDH levels in the supernatants of H9c2 cells were detected using the corresponding kits (Jiancheng Bioengineering Institute, Nanjing, China), and the absorbance was measured at $450 \mathrm{~nm}$. Commercial kits were also used to measure SOD, COX-2, and iNOS levels, as well as MDA activity (Jiancheng Institute of Biotechnology, Nanjing, China) according to the manufacturer's protocols. IL- $1 \beta$, IL-6, MCP-1, TNF- $\alpha$, and NF-kBp65 levels were measured by ELISA using the corresponding kits (Jiancheng Bioengineering Institute, Nanjing, China) according to the manufacturer's instructions.

\subsection{Measurement of ROS Levels}

Intracellular ROS levels were measured by the ROS Assay Kit (Solarbio Science \& Technology Co., Ltd., Beijing, China) using the fluorescence indicator $2^{\prime}, 7^{\prime}$-dichlorodihydrofluorescein diacetate (DCFH-DA) probe [89]. Briefly, H9C2 cells were washed thrice with PBS and incu- 
bated with $10 \mu \mathrm{M}$ DCFH-DA for $20 \mathrm{~min}$ at $37^{\circ} \mathrm{C}$ in the dark. After washing thrice with PBS, the fluorescence intensity of the suspension was measured at the excitation wavelength of $88 \mathrm{~nm}$ and emission wavelength of $525 \mathrm{~nm}$ using a microplate reader (SpectraMax M5, San Diego, CA, USA). Image-Pro Plus 6.0 software (Media Cybernetics Inc, Rockville, MD, USA) was used to measure the mean fluorescence intensity.

\subsection{Western Blotting}

Total protein was extracted from H9c2 cells using RIPA lysis buffer and quantified with the BCA method (Biotek Biomedical Technology Co., Ltd., Beijing, China). The protein samples were resolved by SDS-PAGE and then transferred onto a PVDF membrane (Millipore, Boston, MA, USA). After blocking in 5\% skim milk at room temperature for $1 \mathrm{~h}$, the membrane was incubated overnight with antibodies targeting p-NFkBp65, NFkBp65, p-JNK, JNK, p38 (3031, 6956, 9255, 3708, and 8690, Cell Signaling Technology, Danvers, MA, USA), p-p38, Caspase-9, Caspase-3 (bs-0636r, bs-0049R, bs-0081R, Boosen Biotechnology Co., Ltd., Beijing, China), Bax (ab32503, Abcam, Cambridge, MA, USA), and Bcl-2 (AF6139, Affinity Biosciences, Cincinnati, $\mathrm{OH}, \mathrm{USA})$ at $4{ }^{\circ} \mathrm{C}$. The following day, the membrane was washed thrice with TBST for $10 \mathrm{~min}$ each and incubated with the secondary antibody (MD912565, Biosco Biomedical Technology Co., Ltd., Beijing, China) for $1 \mathrm{~h}$ at room temperature. After washing thrice with TBST, the membrane was imaged using the ChemiDoc MP system (Bio-Rad Laboratories, Hercules, CA, USA). The grey scale values of the protein bands were quantified using ImagePro Plus 7.0 software, and $\beta$-actin was used as the internal reference.

\subsection{Immunofluorescence}

An immunofluorescence assay was performed as previously described. Briefly, the cell climbing slices were rinsed twice with PBS for 3 min each and fixed in $4 \%$ paraformaldehyde for 15 min. After washing again with PBS, the slices were blocked in PBS containing 5\% goat serum for $1 \mathrm{~h}$ and incubated overnight with anti-Nrf2 (ab31163, Abcam, Cambridge, MA, USA) and anti-NF-kBp65 (ab16502, Abcam, Cambridge, MA, USA) antibodies in a humidified box at $4{ }^{\circ} \mathrm{C}$. After the incubation with the secondary antibodies for $1 \mathrm{~h}$, the cells were washed with PBS and counterstained with DAPI (Beyotime Institute of Biotechnology, Shanghai, China) for 5 min at room temperature. The slides were washed thrice with PBS for $5 \mathrm{~min}$ each and observed under a fluorescence microscope at 400x magnification. The average fluorescence intensity was measured using the Image-Pro Plus 6.0 software.

\subsection{Statistical Analysis}

Statistical analysis was performed using SPSS software 22.0 (IBM Corp., Armonk, NY, USA). The results were obtained from at least three independent experiments and indicated as mean \pm standard deviation (SD). The comparison of multiple groups was performed by one-way analysis of variance. A value of $p<005$ was considered statistically significant.

\section{Conclusions}

In this study, UHPLC-MS and network pharmacology were used to evaluate the multiple chemical components, multiple biological processes, and multiple signaling pathways involved in MIRI and in the effect of $O$. falcata, and the results were confirmed by in vitro experiments. O. falcata protected against MIRI by regulating inflammatory response, oxidative stress, and apoptosis by targeting the ROS mediated JNK/p38MAPK/NF- $\mathrm{B}$ signaling pathway. These findings lay the foundation for the clinical application of $O$. falcata against MIRI.

Supplementary Materials: The following supporting information are available online, Table S1: The active compounds in O. falcata. Table S2: The targets of myocardial ischemia reperfusion injury. Table S3: The targets of active compounds in O. falcata. Table S4: The overlapping targets of active compounds and MIRI. Table S5: PPI network analysis of overlapping targets. Table S6: The network analysis of drug-compound-disease-target network. Table S7: Biological process analyses of the overlapping targets. Table S8: Cellular component analyses of the overlapping targets. Table S9: Molecular 
function analysis of the overlapping targets. Table S10: KEGG pathway analyses of the overlapping targets. Figure S1: Effect of other fractions of $O$. falcata on H9c2 cell injury. Figure S2. The ESI negative and positive ion mode. Figure S3: The structure of major compounds.

Author Contributions: Conceptualization, Y.G. and D.-J.Z.; methodology, B.-Y.Z., L.C.C. and Z.-Q.L.; software, Y.G. and Y.-F.P.; validation, Y.G., Y.-F.P. and X.-X.Z.; formal analysis, B.-Y.Z., Z.-Q.L. and X.-X.Z.; investigation, X.-X.Z. and B.-Y.Z.; data curation, Y.G. and Y.-F.P.; writing-original draft preparation, Y.G.; writing-review and editing, B.-Y.Z. and L.C.C.; visualization, Y.G. and Y.-F.P.; supervision, D.-J.Z.; project administration, D.-J.Z.; funding acquisition, D.-J.Z. All authors have read and agreed to the published version of the manuscript.

Funding: This research was funded by the Technology Department project of Qinghai Science (No. 2020-ZJ-922).

Institutional Review Board Statement: Not applicable.

Informed Consent Statement: Not applicable.

Data Availability Statement: Processed data are contained within the article. Raw data are available from the corresponding author upon request.

Acknowledgments: The authors would like to thank the Natural Product Research Application and Development Laboratory of College of Eco-Environmental Engineering of Qinghai University and State Key Laboratory of Plateau Ecology and Agriculture of Qinghai University for their assistance and cooperation during the present study.

Conflicts of Interest: The authors declare that there are no conflicts of interest. The funders had no role in the design of the study; in the collection, analyses, or interpretation of data; in the writing of the manuscript; or in the decision to publish the results.

\section{References}

1. Kisa, A.; Kisa, S.; GBD 2019 Stroke Collaborators. Global, regional, and national burden of stroke and its risk factors, 1990-2019: A systematic analysis for the Global Burden of Disease Study 2019. Lancet Neurol. 2021, 26, 795-820.

2. Bellis, A.; Di Gioia, G.; Mauro, C.; Mancusi, C.; Barbato, E.; Izzo, R.; Trimarco, B.; Morisco, C. Reducing Cardiac Injury during ST-Elevation Myocardial Infarction: A Reasoned Approach to a Multitarget Therapeutic Strategy. J. Clin. Med. 2021, 10, 2968. [CrossRef] [PubMed]

3. Heusch, G. Myocardial ischaemia-reperfusion injury and cardioprotection in perspective. Nat. Rev. Cardiol. 2020, 17, 773-789. [CrossRef] [PubMed]

4. $\quad$ Ekeloef, S.; Koyuncu, S.; Holst-Knudsen, J.; Gundel, O.; Meyhoff, C.S.; Homilius, M.; Stilling, M.; Ekeloef, P.; Münster, A.M.B.; Mathiesen, O.; et al. Cardiovascular events in patients undergoing hip fracture surgery treated with remote ischaemic preconditioning: 1-year follow-up of a randomised clinical trial. Anaesthesia 2021, 76, 1042-1050. [CrossRef] [PubMed]

5. $\quad$ Madsen, J.M.; Glinge, C.; Jabbari, R.; Nepper-Christensen, L.; Høfsten, D.E.; Tilsted, H.-H.; Holmvang, L.; Pedersen, F.; Joshi, F.R.; Sørensen, R.; et al. Comparison of Effect of Ischemic Postconditioning on Cardiovascular Mortality in Patients with ST-Segment Elevation Myocardial Infarction Treated with Primary Percutaneous Coronary Intervention with versus without Thrombectomy. Am. J. Cardiol. 2021, 166, 18-24. [CrossRef]

6. Saccaro, L.F.; Aimo, A.; Emdin, M.; Pico, F. Remote Ischemic Conditioning in Ischemic Stroke and Myocardial Infarction: Similarities and Differences. Front. Neurol. 2021, 12, 716316. [CrossRef]

7. Shen, S.; Ye, J.; Wu, X.; Li, X. Association of N-terminal pro-brain natriuretic peptide level with adverse outcomes in patients with acute myocardial infarction: A meta-analysis. Heart Lung 2021, 50, 863-869. [CrossRef]

8. Torregroza, C.; Yueksel, B.; Ruske, R.; Stroethoff, M.; Raupach, A.; Heinen, A.; Hollmann, M.W.; Huhn, R.; Feige, K. Combination of Cyclosporine A and Levosimendan Induces Cardioprotection under Acute Hyperglycemia. Int. J. Mol. Sci. 2021, $22,4517$. [CrossRef]

9. Procopio, M.C.; Lauro, R.; Nasso, C.; Carerj, S.; Squadrito, F.; Bitto, A.; Di Bella, G.; Micari, A.; Irrera, N.; Costa, F. Role of Adenosine and Purinergic Receptors in Myocardial Infarction: Focus on Different Signal Transduction Pathways. Biomedicines 2021, 9, 204. [CrossRef]

10. Zuo, J.; Park, C.; Kung, J.Y.C.; Bou-Chacra, N.A.; Doschak, M.; Löbenberg, R. Traditional Chinese Medicine "Pill”, an Ancient Dosage Form with Surprising Modern Pharmaceutical Characteristics. Pharm. Res. 2021, 38, 199-211. [CrossRef]

11. Xie, F.; Wu, Y.-Y.; Duan, G.-J.; Wang, B.; Gao, F.; Wei, P.-F.; Chen, L.; Liu, A.P.; Li, M. Anti-Myocardial Ischemia Reperfusion Injury Mechanism of Dried Ginger-Aconite Decoction Based on Network Pharmacology. Front. Pharmacol. 2021, 12, 609702. [CrossRef] [PubMed] 
12. Cao, L.; Gao, Y.; Zhu, J.; Zhang, J.; Dong, M.; Mao, Y. Protective action of the ginsenoside Rh3 in a rat myocardial ischemiareperfusion injury model by inhibition of apoptosis induced via p38 mitogen-activated protein kinase/caspase- 3 signaling. J. Int. Med. Res. 2020, 48, 300060520969090. [CrossRef] [PubMed]

13. Wang, R.; Wang, M.; Zhou, J.; Wu, D.; Ye, J.; Sun, G.; Sun, X. Saponins in Chinese Herbal Medicine Exerts Protection in Myocardial Ischemia-Reperfusion Injury: Possible Mechanism and Target Analysis. Front. Pharmacol. 2020, 11, 570867. [CrossRef] [PubMed]

14. Vedarathinam, R.C.; Rajkumar, Y.; Vetriselvan, P.; Prem, P.N.; Ganapathy, A.; Kurian, G.A. Resveratrol-mediated cardioprotection against myocardial ischemia-reperfusion injury was revoked by statin-induced mitochondrial alterations. Drug Chem. Toxicol. 2021, 1-9. [CrossRef]

15. Zhang, L.; Song, J.; Kong, L.; Yuan, T.; Li, W.; Zhang, W.; Hou, B.; Lu, Y.; Du, G. The strategies and techniques of drug discovery from natural products. Pharmacol. Ther. 2020, 216, 107686. [CrossRef]

16. Wu, Z.; Raven, P.H.; Hong, D. Flora of China; Science Press: St. Louis, MO, USA, 1998; Volume 49.

17. Jiang, H.; Hu, J.R.; Zhan, W.Q.; Liu, X. Screening for fractions of Oxytropis falcata Bunge with antibacterial activity. Nat. Prod. Res. 2009, 23, 953-959. [CrossRef] [PubMed]

18. Yan, H.Y.; Gao, L.M. Study on the Chemical Constituents of Oxytropis falcata Bunge. Nat. Prod. Res. Dev. 2009, 21, 246-248.

19. Yang, H.; Dong, W.; Li, T.; Cai, B. Flavonoid aglycones of Oxytropis falcata. Chem. Nat. Compd. 2009, 45, $239-241$.

20. Gong, X.; Xiong, H.; Liu, S.; Liu, Y.; Yin, L.; Tu, C.; Wang, H.; Zhao, Z.; Chen, W.; Mei, Z. Qingpeng Ointment Ameliorates Inflammatory Responses and Dysregulation of Itch-Related Molecules for Its Antipruritic Effects in Experimental Allergic Contact Dermatitis. Front. Pharmacol. 2019, 10, 354. [CrossRef]

21. Zhang, F.; Caifeng, L.; Na, Z.; Xiaorui, Z.; Jianzhi, C.; Shasha, G.; Junqi, W. A network pharmacological study on the potential mechanism of Shierwei Yishou San in the treatment of Nian Yu Nai. World Sci. Technol.-Mod. Tradit. Chin. Med. 2021, 23, 1978-1987. [CrossRef]

22. Yang, S.; Zhang, Y.; Lin, X.; Wen, J.; Bai, X. Systematic review on clinical efficacy and safety of Cheezheng Pain Relieving Plaster for soft tissue injury. Chin. J. Tradit. Chin. Med. 2020, 45, 431-438. [CrossRef]

23. Zhang, D.; Yuan, W.; Zhang, B.; Hong, E.K.; Shi, P.; Yang, Z.; Zhang, Y.; Wang, H. Analysis of chemical constituents in the extract and rat serum from the chloroform extract of Oxytropis falcata Bunge by HPLC-MS. Pak. J. Pharm. Sci. 2020, 33, 669-674. [PubMed]

24. Jiang, H.; Zhan, W.Q.; Liu, X.; Jiang, S.X. Antioxidant activities of extracts and flavonoid compounds from Oxytropis falcata Bunge. Nat. Prod. Res. 2008, 22, 1650-1656. [CrossRef] [PubMed]

25. Wang, Y.-J.; Li, Y.; Wang, X.-L.; Li, X.-Z.; Chen, Y.-W.; Yang, L.-L.; Ming, H.-X. Effect of Total Flavonoids of Bunge on the Expression of p-JAK1-and p-STAT1-Related Proteins in Idiopathic Pulmonary Fibrosis. Evid. Based Complement. Alternat. Med. 2020, 2020, 2407239. [CrossRef] [PubMed]

26. Zeng, Q.; Cai, X.; Cao, Y.; Zhou, C.; Yu, L.; Chen, J. Preparation, characterization, and pharmacodynamic study on deep second degree burns of total flavonoids composite phospholipids liposome gel of Bunge. Drug Dev. Ind. Pharm. 2020, 46, 2000-2009. [CrossRef]

27. Yang, L.; Wang, Z.; Jiang, L.; Sun, W.; Fan, Q.; Liu, T. Total Flavonoids Extracted from Bunge Improve Insulin Resistance through Regulation on the IKK/NF-B Inflammatory Pathway. Evid.-Based Complement. Alternat. Med. 2017, 2017, 2405124. [CrossRef]

28. Ahmed, S.; Ahmed, N.; Rungatscher, A.; Linardi, D.; Kulsoom, B.; Innamorati, G.; Meo, S.A.; Gebrie, M.A.; Mani, R.; Merigo, F.; et al. Cocoa Flavonoids Reduce Inflammation and Oxidative Stress in a Myocardial Ischemia-Reperfusion Experimental Model. Antioxidants 2020, 9, 167. [CrossRef]

29. Zhang, H.-J.; Chen, R.-C.; Sun, G.-B.; Yang, L.-P.; Zhu, Y.-d.; Xu, X.-D.; Sun, X.-B. Protective effects of total flavonoids from Clinopodium chinense (Benth.) O. Ktze on myocardial injury in vivo and in vitro via regulation of Akt/Nrf2/HO-1 pathway. Phytomedicine 2018, 40, 88-97. [CrossRef]

30. Zhang, X.; Wang, Y.; Shen, W.; Ma, S.; Chen, W.; Qi, R. Rosa rugosa flavonoids alleviate myocardial ischemia reperfusion injury in mice by suppressing JNK and p38 MAPK. Microcirculation 2017, 24, e12385. [CrossRef]

31. Ma, Y.; Wen, J.; Lu, D.; Zheng, Q.; Li, Y.; Zhang, D. Protective Effects of Medicine Oxytropis falcata Bunge on Hypoxia/Reoxygen Injury in H9C2 Cardiomyocytes. Genom. Appl. Biol. 2017, 36, 1180-1183. [CrossRef]

32. Li, Z.; Liu, M.; Li, F.; Ren, S.; Ma, J.; Zhang, D. The Antioxidative Effect of Oxytropis falcata Bunge Ethanol Extract on Rats' Hearts Against Myocardial Ischemia and Reperfusion Injury. Nat. Prod. Res. Dev. 2014, 26, 423-427.

33. Du, H.; Liu, M.; Li, F.; Ren, S.; Ma, J.; Zhang, D. Influence of Oxytropis falcata Bunge on expression of Bcl-2 and Bax of myocardial ischemia and reperfusion injury in Rats. J. Qinghai Med. Coll. 2013, 34, 203-206.

34. Gao, L.; Cao, M.; Li, J.-Q.; Qin, X.-M.; Fang, J. Traditional Chinese Medicine Network Pharmacology in Cardiovascular Precision Medicine. Curr. Pharm. Des. 2021, 27, 2925-2933. [CrossRef] [PubMed]

35. Shawky, E. Prediction of potential cancer-related molecular targets of North African plants constituents using network pharmacology-based analysis. J. Ethnopharmacol. 2019, 238, 111826. [CrossRef] [PubMed]

36. Yang, J.; Tian, S.; Zhao, J.; Zhang, W. Exploring the mechanism of TCM formulae in the treatment of different types of coronary heart disease by network pharmacology and machining learning. Pharmacol. Res. 2020, 159, 105034. [CrossRef] [PubMed]

37. Zhang, R.; Zhu, X.; Bai, H.; Ning, K. Network Pharmacology Databases for Traditional Chinese Medicine: Review and Assessment. Front. Pharmacol. 2019, 10, 123. [CrossRef] 
38. He, L.; Jiang, H.; Lan, T.; Qiu, Y.; Yang, K.; Chen, K.; Yao, X.; Yao, Z.; Lu, W. Chemical profile and potential mechanisms of Huo-Tan-Chu-Shi decoction in the treatment of coronary heart disease by UHPLC-Q/TOF-MS in combination with network pharmacology analysis and experimental verification. J. Chromatogr. B Anal. Technol. Biomed. Life Sci. 2021, 1175, 122729. [CrossRef]

39. Jia, L.-Y.; Cao, G.-Y.; Li, J.; Gan, L.; Li, J.-X.; Lan, X.-Y.; Meng, Z.-Q.; He, X.; Zhang, C.-F.; Wang, C.-Z.; et al. Investigating the Pharmacological Mechanisms of SheXiang XinTongNing Against Coronary Heart Disease Based on Network Pharmacology and Experimental Evaluation. Front. Pharmacol. 2021, 12, 698981. [CrossRef]

40. Jin, Y.; Yin, X.; Li, Z.; Xu, J. Mechanism of Baihe Decoction in the treatment of coronary heart disease based on network pharmacology and molecular docking. Ann. Palliat. Med. 2021, 10, 3205-3218. [CrossRef]

41. Zhang, J.; Liang, R.; Wang, L.; Yang, B. Effects and mechanisms of Danshen-Shanzha herb-pair for atherosclerosis treatment using network pharmacology and experimental pharmacology. J. Ethnopharmacol. 2019, 229, 104-114. [CrossRef]

42. Cui, S.; Chen, S.; Wu, Q.; Chen, T.; Li, S. A network pharmacology approach to investigate the anti-inflammatory mechanism of effective ingredients from Salvia miltiorrhiza. Int. Immunopharmacol. 2020, 81, 106040. [CrossRef] [PubMed]

43. Zhang, Y.; Wang, J.; Liu, Y.-M.; Chen, Y.-Y.; Yang, X.-C.; Duan, L. The Synergistic Effects of and on Coronary Heart Disease Identified by Network Pharmacology and Experiment. Drug Des. Dev. Ther. 2021, 15, 4053-4069. [CrossRef] [PubMed]

44. Umme, H.; Kandagalla, S.; Sharath, B.S.; Jyothsna, K.; Manjunatha, H. Network Pharmacology Approach Uncovering Pathways Involved in Targeting Hsp90 Through Curcumin and Epigallocatechin to Control Inflammation. Curr. Drug Discov. Technol. 2021, 18, 127-138. [CrossRef] [PubMed]

45. Ding, H.; Chen, L.; Hong, Z.; Yu, X.; Wang, Z.; Feng, J. Network pharmacology-based identification of the key mechanism of quercetin acting on hemochromatosis. Metallomics 2021, 13, mfab025. [CrossRef] [PubMed]

46. Ju, Y.; Liang, H.; Du, K.; Guo, Z.; Meng, D. Isolation of triterpenoids and phytosterones from Bl. to treat breast cancer based on network pharmacology. Nat. Prod. Res. 2021, 35, 5939-5942. [CrossRef] [PubMed]

47. Zhang, M.-R.; Jiang, K.; Yang, J.-L.; Shi, Y.-P. Flavonoids as key bioactive components of bunge, a traditional anti-inflammatory and analgesic Tibetan medicine. Nat. Prod. Res. 2020, 34, 3335-3352. [CrossRef]

48. Chen, X.; Li, H.; Tian, L.; Li, Q.; Luo, J.; Zhang, Y. Analysis of the Physicochemical Properties of Acaricides Based on Lipinski's Rule of Five. J. Comput. Biol. 2020, 27, 1397-1406. [CrossRef]

49. Tsiklauri, L.; Švík, K.; Chrastina, M.; Poništ, S.; Dráfi, F.; Slovák, L.; Alania, M.; Kemertelidze, E.; Bauerova, K. Bioflavonoid Robinin from Lam. Mildly Improves the Effect of Metothrexate in Rats with Adjuvant Arthritis. Nutrients 2021, $13,1268$. [CrossRef]

50. Zhang, Q.; Zhao, Y.; Zhang, M.; Zhang, Y.; Ji, H.; Shen, L. Recent advances in research on vine tea, a potential and functional herbal tea with dihydromyricetin and myricetin as major bioactive compounds. J. Pharm. Anal. 2021, 11, 555-563. [CrossRef]

51. Papatheodorou, I.; Galatou, E.; Panagiotidis, G.-D.; Ravingerová, T.; Lazou, A. Cardioprotective Effects of PPAR $\beta / \delta$ Activation against Ischemia/Reperfusion Injury in Rat Heart Are Associated with ALDH2 Upregulation, Amelioration of Oxidative Stress and Preservation of Mitochondrial Energy Production. Int. J. Mol. Sci. 2021, 22, 6399. [CrossRef]

52. Vashi, R.; Patel, B.M. NRF2 in Cardiovascular Diseases: A Ray of Hope! J. Cardiovasc. Transl. Res. 2021, 14, 573-586. [CrossRef] [PubMed]

53. Rahim, I.; Sayed, R.K.; Fernández-Ortiz, M.; Aranda-Martínez, P.; Guerra-Librero, A.; Fernández-Martínez, J.; Rusanova, I.; Escames, G.; Djerdjouri, B.; Acuña-Castroviejo, D. Melatonin alleviates sepsis-induced heart injury through activating the Nrf2 pathway and inhibiting the NLRP3 inflammasome. Naunyn-Schmiedebergs Arch. Pharmacol. 2021, 394, 261-277. [CrossRef] [PubMed]

54. Liu, K.; Wang, F.; Wang, S.; Li, W.-N.; Ye, Q. Mangiferin Attenuates Myocardial Ischemia-Reperfusion Injury via MAPK/Nrf2/HO-1/NF-kB in vitro and in vivo. Oxid. Med. Cell. Longev. 2019, 2019, 7285434. [CrossRef] [PubMed]

55. Zhou, W.; Cai, D. Midazolam suppresses ischemia/reperfusion-induced cardiomyocyte apoptosis by inhibiting the JNK/p38 MAPK signaling pathway. Can. J. Physiol. Pharmacol. 2021, 100, 1-8. [CrossRef] [PubMed]

56. Wang, K.; Li, Y.; Qiang, T.; Chen, J.; Wang, X. Role of epigenetic regulation in myocardial ischemia/reperfusion injury. Pharmacol. Res. 2021, 170, 105743. [CrossRef] [PubMed]

57. Wu, Y.; Liu, H.; Wang, X. Cardioprotection of pharmacological postconditioning on myocardial ischemia/reperfusion injury. Life Sci. 2021, 264, 118628. [CrossRef] [PubMed]

58. Gunata, M.; Parlakpinar, H. A review of myocardial ischaemia/reperfusion injury: Pathophysiology, experimental models, biomarkers, genetics and pharmacological treatment. Cell Biochem. Funct. 2021, 39, 190-217. [CrossRef] [PubMed]

59. Newman, D.J.; Cragg, G.M. Natural Products as Sources of New Drugs over the Nearly Four Decades from 01/1981 to 09/2019. J. Nat. Prod. 2020, 83, 770-803. [CrossRef]

60. Wang, J.; Wang, H.; Mou, X.; Luan, M.; Zhang, X.; He, X.; Zhao, F.; Meng, Q. The Advances on the Protective Effects of Ginsenosides on Myocardial Ischemia and Ischemia-Reperfusion Injury. Mini Rev. Med. Chem. 2020, 20, 1610-1618. [CrossRef]

61. Ma, H.; Hao, J.; Liu, H.; Yin, J.; Qiang, M.; Liu, M.; He, S.; Zeng, D.; Liu, X.; Lian, C.; et al. Peoniflorin Preconditioning Protects Against Myocardial Ischemia/Reperfusion Injury Through Inhibiting Myocardial Apoptosis: RISK Pathway Involved. Appl. Biochem. Biotechnol. 2021, 194, 1149-1165. [CrossRef] 
62. Chen, Q.; Zhang, P.; Xiao, Q.-X.; Liu, Q.; Zhang, Y. Protective effect of Shengmai injection on myocardial endothelial cell glycoprotein detachment after myocardial ischemia-reperfusion injury in isolated rat hearts. Perfusion 2021, 36, 757-765. [CrossRef] [PubMed]

63. Watkins, S.J.; Borthwick, G.M.; Arthur, H.M. The H9C2 cell line and primary neonatal cardiomyocyte cells show similar hypertrophic responses in vitro. In Vitro Cell. Dev. Biol. Anim. 2011, 47, 125-131. [CrossRef] [PubMed]

64. Qiu, Y.; Cong, N.; Liang, M.; Wang, Y.; Wang, J. Systems Pharmacology Dissection of the Protective Effect of Myricetin Against Acute Ischemia/Reperfusion-Induced Myocardial Injury in Isolated Rat Heart. Cardiovasc. Toxicol. 2017, 17, 277-286. [CrossRef] [PubMed]

65. Janeesh, P.A.; Abraham, A. Robinin modulates doxorubicin-induced cardiac apoptosis by TGF- $\beta 1$ signaling pathway in Sprague Dawley rats. Biomed. Pharmacother. 2014, 68, 989-998. [CrossRef]

66. Kim, J.W.; Jin, Y.C.; Kim, Y.M.; Rhie, S.; Kim, H.J.; Seo, H.G.; Lee, J.H.; Ha, Y.L.; Chang, K.C. Daidzein administration in vivo reduces myocardial injury in a rat ischemia/reperfusion model by inhibiting NF-kappaB activation. Life Sci. 2009, 84, 227-234. [CrossRef]

67. Yu, D.; Li, M.; Tian, Y.; Liu, J.; Shang, J. Luteolin inhibits ROS-activated MAPK pathway in myocardial ischemia/reperfusion injury. Life Sci. 2015, 122, 15-25. [CrossRef]

68. Li, J.P.; Yan, R.; Ma, P.L.; Fu, P.; Tian, H.T.; Wang, L.L. Effects of luteolin in different doses on the cardiomyocyte apoptosis in rats with myocardial ischemia reperfusion. J. Biol. Regul. Homeost. Agents 2020, 34, 2311-2315. [CrossRef]

69. Yu, L.-M.; Dong, X.; Zhang, J.; Li, Z.; Xue, X.-D.; Wu, H.-J.; Yang, Z.-L.; Yang, Y.; Wang, H.-S. Naringenin Attenuates Myocardial Ischemia-Reperfusion Injury via cGMP-PKGI Signaling and In Vivo and In Vitro Studies. Oxid. Med. Cell. Longev. 2019, 2019, 7670854. [CrossRef]

70. Xu, S.; Wu, B.; Zhong, B.; Lin, L.; Ding, Y.; Jin, X.; Huang, Z.; Lin, M.; Wu, H.; Xu, D. Naringenin alleviates myocardial ischemia/reperfusion injury by regulating the nuclear factor-erythroid factor 2-related factor 2 (Nrf2)/System xc-/glutathione peroxidase 4 (GPX4) axis to inhibit ferroptosis. Bioengineered 2021, 12, 10924-10934. [CrossRef]

71. Gu, X.; Shi, Y.; Chen, X.; Sun, Z.; Luo, W.; Hu, X.; Jin, G.; You, S.; Qian, Y.; Wu, W.; et al. Isoliquiritigenin attenuates diabetic cardiomyopathy via inhibition of hyperglycemia-induced inflammatory response and oxidative stress. Phytomedicine 2020, 78, 153319. [CrossRef]

72. Sengupta, B.; Sahihi, M.; Dehkhodaei, M.; Kelly, D.; Arany, I. Differential roles of 3-Hydroxyflavone and 7-Hydroxyflavone against nicotine-induced oxidative stress in rat renal proximal tubule cells. PLoS ONE 2017, 12, e0179777. [CrossRef]

73. Liao, Y.; Tan, R.-Z.; Li, J.-C.; Liu, T.-T.; Zhong, X.; Yan, Y.; Yang, J.-K.; Lin, X.; Fan, J.-M.; Wang, L. Isoliquiritigenin Attenuates UUO-Induced Renal Inflammation and Fibrosis by Inhibiting Mincle/Syk/NF-Kappa B Signaling Pathway. Drug Des. Dev. Ther. 2020, 14, 1455-1468. [CrossRef]

74. Khan, S.I.; Malhotra, R.K.; Rani, N.; Sahu, A.K.; Tomar, A.; Garg, S.; Nag, T.C.; Ray, R.; Ojha, S.; Arya, D.S.; et al. Febuxostat Modulates MAPK/NF-Bp65/TNF- Signaling in Cardiac Ischemia-Reperfusion Injury. Oxid. Med. Cell. Longev. 2017, 2017, 8095825. [CrossRef]

75. Lu, C.; Liu, L.; Chen, S.; Niu, J.; Li, S.; Xie, W.; Cheng, X. Azathioprine pretreatment ameliorates myocardial ischaemia reperfusion injury in diabetic rats by reducing oxidative stress, apoptosis, and inflammation. Clin. Exp. Pharmacol. Physiol. 2021, 48, 1621-1632. [CrossRef]

76. Zhao, W.; Cao, L.; Ying, H.; Zhang, W.; Li, D.; Zhu, X.; Xue, W.; Wu, S.; Cao, M.; Fu, C.; et al. Endothelial CDS2 deficiency causes VEGFA-mediated vascular regression and tumor inhibition. Cell Res. 2019, 29, 895-910. [CrossRef] [PubMed]

77. Rusinkevich, V.; Huang, Y.; Chen, Z.-Y.; Qiang, W.; Wang, Y.-G.; Shi, Y.-F.; Yang, H.-T. Temporal dynamics of immune response following prolonged myocardial ischemia/reperfusion with and without cyclosporine A. Acta Pharmacol. Sin. 2019, 40, 1168-1183 [CrossRef] [PubMed]

78. Guo, Y.; Nong, Y.; Tukaye, D.N.; Rokosh, G.; Du, J.; Zhu, X.; Book, M.; Tomlin, A.; Li, Q.; Bolli, R. Inducible cardiac-specific overexpression of cyclooxygenase-2 (COX-2) confers resistance to ischemia/reperfusion injury. Basic Res. Cardiol. 2019, 114, 32. [CrossRef] [PubMed]

79. Szabó, M.R.; Pipicz, M.; Csont, T.; Csonka, C. Modulatory Effect of Myokines on Reactive Oxygen Species in Ischemia/Reperfusion. Int. J. Mol. Sci. 2020, 21, 9382. [CrossRef]

80. Zhang, Q.; Deng, Y.; Lai, W.; Guan, X.; Sun, X.; Han, Q.; Wang, F.; Pan, X.; Ji, Y.; Luo, H.; et al. Maternal inflammation activated ROS-p38 MAPK predisposes offspring to heart damages caused by isoproterenol via augmenting ROS generation. Sci. Rep. 2016, 6, 30146. [CrossRef]

81. Pei, Y.; Cui, F.; Du, X.; Shang, G.; Xiao, W.; Yang, X.; Cui, Q. Antioxidative nanofullerol inhibits macrophage activation and development of osteoarthritis in rats. Int. J. Nanomed. 2019, 14, 4145-4155. [CrossRef]

82. Wang, Q.; Liu, A.-D.; Li, T.-S.; Tang, Q.; Wang, X.-C.; Chen, X.-B. Ghrelin ameliorates cardiac fibrosis after myocardial infarction by regulating the Nrf2/NADPH/ROS pathway. Peptides 2021, 144, 170613. [CrossRef] [PubMed]

83. Sun, T.; Zhang, Y.; Zhong, S.; Gao, F.; Chen, Y.; Wang, B.; Cai, W.; Zhang, Z.; Li, W.; Lu, S.; et al. N-n-Butyl Haloperidol Iodide, a Derivative of the Anti-psychotic Haloperidol, Antagonizes Hypoxia/Reoxygenation Injury by Inhibiting an Egr-1/ROS Positive Feedback Loop in H9c2 Cells. Front. Pharmacol. 2018, 9, 19. [CrossRef] [PubMed] 
84. Zhang, M.; Lei, Y.-S.; Meng, X.-W.; Liu, H.-Y.; Li, L.-G.; Zhang, J.; Zhang, J.-X.; Tao, W.-H.; Peng, K.; Lin, J.; et al. Iguratimod Alleviates Myocardial Ischemia/Reperfusion Injury through Inhibiting Inflammatory Response Induced by Cardiac Fibroblast Pyroptosis via COX2/NLRP3 Signaling Pathway. Front. Cell Dev. Biol. 2021, 9, 746317. [CrossRef] [PubMed]

85. Valikeserlis, I.; Athanasiou, A.-A.; Stakos, D. Cellular mechanisms and pathways in myocardial reperfusion injury. Coron. Artery Dis. 2021, 32, 567-577. [CrossRef]

86. Peng, K.; Liu, H.; Yan, B.; Meng, X.-W.; Song, S.-Y.; Ji, F.-H.; Xia, Z. Inhibition of cathepsin S attenuates myocardial ischemia/reperfusion injury by suppressing inflammation and apoptosis. J. Cell. Physiol. 2021, 236, 1309-1320. [CrossRef] [PubMed]

87. Woodman, O.L.; Chin, K.Y.; Thomas, C.J.; Ng, D.C.H.; May, C.N. Flavonols and Flavones—Protecting Against Myocardial Ischemia/Reperfusion Injury by Targeting Protein Kinases. Curr. Med. Chem. 2018, 25, 4402-4415. [CrossRef]

88. Du, X.-J.; Wei, J.; Tian, D.; Yan, C.; Hu, P.; Wu, X.; Yang, W.; Hu, X. NEAT1 promotes myocardial ischemia-reperfusion injury via activating the MAPK signaling pathway. J. Cell. Physiol. 2019, 234, 18773-18780. [CrossRef]

89. Wu, Y.; Zhang, J.; Li, C.; Hu, H.; Wang, S. The Activation of ROS/NF-kB/MMP-9 Pathway Promotes Calcium-Induced Kidney Crystal Deposition. Oxid. Med. Cell. Longev. 2021, 2021, 8836355. [CrossRef] 